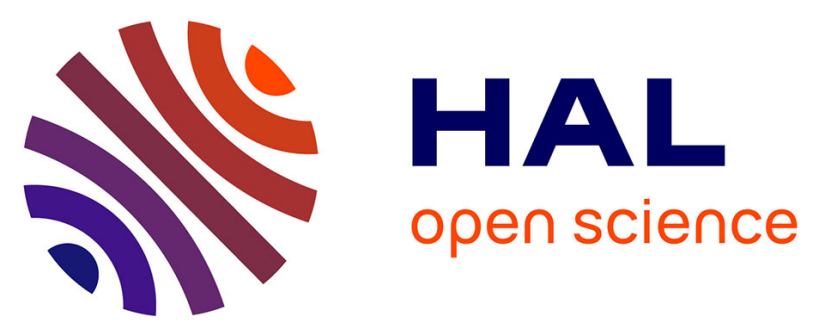

\title{
Synergism between non-thermal plasma and photocatalysis Implicationsin the post discharge of ozone at a pilot scale in a catalytic fixed-bed reactor
}

\author{
W.A. Saoud, A.A. Assadi, M. Guiza, S. Loganathan, A. Bouzaza, W.
}

Aboussaoud, A. Ouederni, S. Rtimi, D. Wolbert

\section{To cite this version:}

W.A. Saoud, A.A. Assadi, M. Guiza, S. Loganathan, A. Bouzaza, et al.. Synergism between non-thermal plasma and photocatalysis Implicationsin the post discharge of ozone at a pilot scale in a catalytic fixed-bed reactor. Applied Catalysis B: Environmental, 2019, 241, pp.227-235. 10.1016/j.apcatb.2018.09.029 . hal-01905109

HAL Id: hal-01905109

https://hal-univ-rennes1.archives-ouvertes.fr/hal-01905109

Submitted on 14 Dec 2018

HAL is a multi-disciplinary open access archive for the deposit and dissemination of scientific research documents, whether they are published or not. The documents may come from teaching and research institutions in France or abroad, or from public or private research centers.
L'archive ouverte pluridisciplinaire HAL, est destinée au dépôt et à la diffusion de documents scientifiques de niveau recherche, publiés ou non, émanant des établissements d'enseignement et de recherche français ou étrangers, des laboratoires publics ou privés. 


\section{Synergism between non-thermal plasma and photocatalysis: Implicationsin the post discharge of ozone at a pilot scale in a catalytic fixed-bed reactor}

Wala Abou Saoud ${ }^{1,2}$, Aymen Amine Assadi ${ }^{1 *}$, Monia Guiza², Sivachandiran Loganathan $^{3}$, Abdelkrim Bouzaza1', Wael Aboussaoud², Abdelmottaleb Ouederni², Sami Rtimi ${ }^{* *}$, Dominique Wolbert ${ }^{1}$

1'Laboratoire Sciences Chimiques de Rennes - équipe Chimie et Ingénierie des Procédés, UMR 6226 CNRS, ENSCR-11, allée de Beaulieu, CS 508307-35708 Rennes, France.

'Laboratory process engineering and industrial systems (GPSI), National School of Engineers of Gabes (ENIG), University of Gabes (UG), Omar Ibn Elkhatab Street, Zrig 6029 Gabes, Tunisia.

${ }^{3}$ Research Institute \& Chemistry Department, SRM University, Kattankulathur, Chennai-India ${ }^{4}$ Ecole Polytechnique Fédérale de Lausanne, EPFL-SB-ISIC-GPAO, Station 6, CH-1015 Lausanne, Switzerland.

* Corresponding authors. E-mails: aymen.assadi@ensc-rennes.fr (A. Assadi) and sami.rtimi@epfl.ch (S. Rtimi); Tel.: +33 223238152.

\section{Graphical abstract}

\section{Photocatalysis}

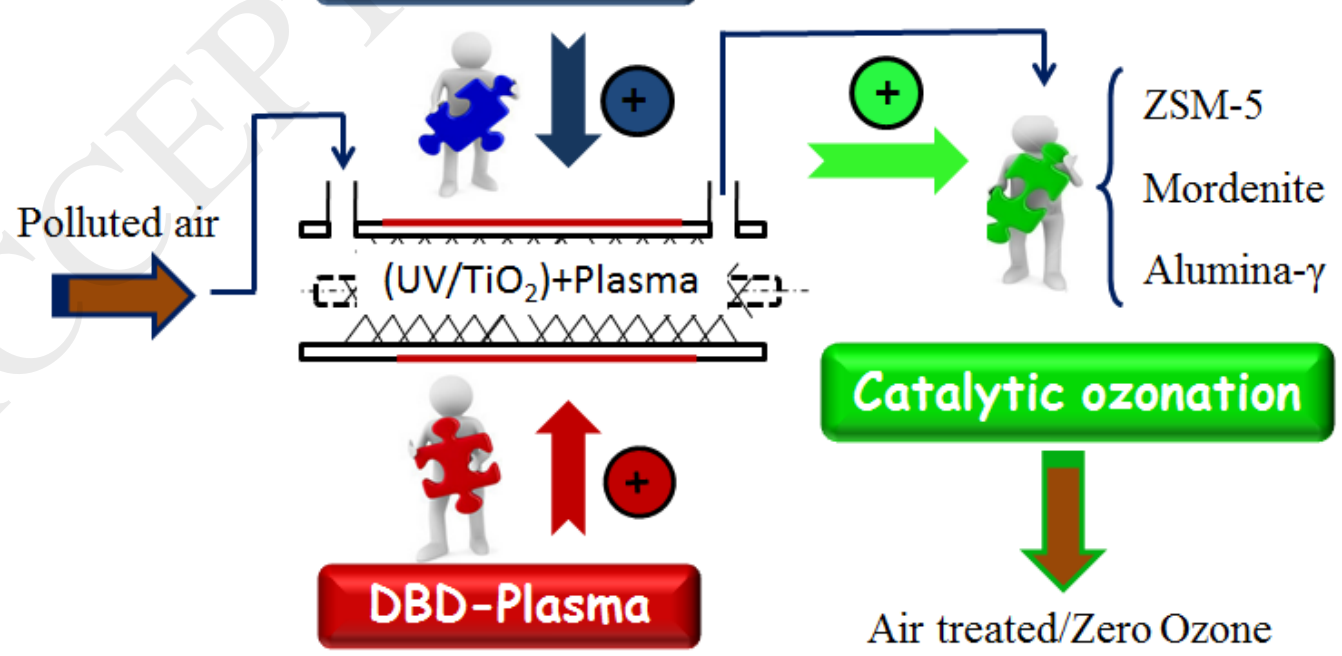




\section{HIGHLIGHTS}

- $\mathrm{C}_{4} \mathrm{H}_{8} \mathrm{O}$ removal using (UV-TiO2/plasma) + catalytic-bed system is studied.

- Specific catalysts are tested for $\mathrm{C}_{4} \mathrm{H}_{8} \mathrm{O} / \mathrm{O}_{3}$ removal at pilot scale.

- Impacts of operating parameters on process performance are defined.

- Highly efficient synergetic association was obtained.

- Better performance in mineralization rate via ozone valorization.

\section{Abstract}

This study focuses on Butyraldehyde $\left(\mathrm{C}_{4} \mathrm{H}_{8} \mathrm{O}\right)$ degradation using catalytic ozonation oriented to the optimization of non-thermal plasma/photocatalytic coupled processes. After the first oxidation by non-thermal plasma coupled photocatalytic processes, a second oxidative step leading to the decomposition of the residual Butyraldehyde by Ozone is catalyzed by Mordenite, ZSM-5 and $\gamma$-alumina. The Butyraldehyde degradation in the presence of Ozone under operational parameters such as plasma energy, Butyraldehyde inlet concentration, relative humidity and the height of the catalytic bed are reported in detail. The optimum operating conditions found were: Qair $=1 \mathrm{~m}^{3} \mathrm{~h}^{-1},\left[\mathrm{C}_{4} \mathrm{H}_{8} \mathrm{O}\right]=100 \mathrm{mg} \mathrm{m}^{-3}$, SIE mediated by ZSM- 5 . The formation of intermediate by-products was monitored during the degradation of Butyraldehyde in the presence of Ozone and ZSM-5 catalyst to suggest a degradation pathway. The coupling of catalytic ozonation by non-thermal plasma/photocatalysis lead to the total decomposition of Ozone when catalyzed by ZSM-5and presents a positive effect on the mineralization capacity. The pollutants degradation intermediates were identified by GC-MS and the oxidative states on the catalytic bed were characterized by XPS.

Keywords: Photocatalytic/non-thermal plasma, catalytic packed bed, Zeolites ZSM5 , Ozone valorization, synergetic effect, air treatment.

\section{Introduction}


Outdoor air pollutants have common sources: industry, transportation, heating and agriculture [1], they affect negatively health and climate. Recently, European directive 2016/2284/EC has outlined the reduction of emissions by 2030 for air pollutants like $\mathrm{NH}_{3}, \mathrm{SO}_{2}, \mathrm{NO}_{x}$, volatile organic compounds (VOCs) (excluding $\mathrm{CH}_{4}$ )) [2]. France, for example, is committed to reduce from $52 \%$ up to $77 \%$ its emissions of VOC, $\mathrm{NO}_{x}$, $\mathrm{SO}_{2}$, and by $13 \%$ ammonia by 2030 [3]. All the processes using a liquid phase combined with an oxi-reduction mechanism (Stretford, Ferrifloc, Sulfurex, BurnerScrubber, Catalyst-Scrubber, Ozone Process, etc.) expensive equipment subject to corrosion [4]. This leads to high investment and maintenance costs, as well as large consumption of chemical reagents and environmental problems created by discharge of the waste effluent after treatment [5]. Processes not requiring corrosive reagents but a power supply and producing only inorganic by-products $\left(\mathrm{CO}_{2}, \mathrm{H}_{2} \mathrm{O}\right)$ are needed at the present time. Technologies "zero waste \& zero reagent" coupling non-thermal plasma (NTP) and Dielectric Barrier Discharge (DBD) with catalytic oxidation look promising to achieve this objective at low energy consumption [6-9]. VOCs removal has been reported including isovaleraldehyde, isovaleric acid, trimethylamine, benzene, ammonia and dimethyl disulfide [10-15]. The amount of ozone produced during VOCs treatment via oxidation processes was observed to be high $>20 \mathrm{ppm}$ [16]. Zeolites have been reported to induce a higher ozone decomposition compared with activated carbons, which are flammable under high concentration of ozone [17, 18]. Thus, the goal of this study is to improve the removal of volatile organic compounds by coupling of DBD-plasma-photocatalysis and catalytic ozonation and its consequences on Butyraldehyde degradation.

The combination of DBD-plasma/photocatalysis/catalytic ozonation was determined to optimize the operating process for better removal of malodors and air pollution. In this work, by adding the zeolite fixed bed reactor to the plasma/photocatalysis reactor we aim to: (i) increase the degradation of the residual butyraldehyde in the fixed bed, and (ii) reduce the amount of ozone created in the plasma/photocatalysis reactor.

\section{Experiment and measurement}

\subsection{Experimental setup}


The experimental setup used to treat VOCs under DBD-plasma/fixed-bed system is shown in Figure 1. The setup includes a control for air stream generation system, two continuous pluck-flow reactors for oxidation step (annular and fixed-bed reactors) gas sampling equipment. The DBD-plasma reactor works in photocatalytic mode and/or in plasma mode or in simultaneous mode. The DBD-plasma reactor consists of two concentric cylinders, one outer cylinder of $76 \mathrm{~mm}$ and an inner cylinder of $58 \mathrm{~mm}$ with wall thickness of $4 \mathrm{~mm}$. Both cylinder are $100 \mathrm{~cm}$ long and contain UV lamp (Philips TL 40W/05). In the active zone of the reactor, between the inner wall of the outer cylinder/outer wall, polluted air stream is treated under UV-light (Ahlstrom Research and Services). The physical properties of the catalyst are given in Table 1.

Table 1. Main characteristics of $\mathrm{TiO}_{2}-\mathrm{GFT}$.

\begin{tabular}{cccc}
\hline Type & BET surface $\left(\mathrm{m}^{2} / \mathrm{g}\right)$ & Crystal structure & Diameter $(\mathrm{nm})$ \\
\hline PC500 & 300 & Anatase $100 \%$ & $5-10$ \\
\hline
\end{tabular}

Thus, UV lamp was placed in the inner concentric cylinder in order to have a homogeneous irradiation. To generate DBD-plasma, high voltage power is applied to the reactor which is covered by a copper grid forming the outer electrode and the inner was made out of Al. The applied voltage is delivered by a generator as a sinusoidal waveform up to $10 \mathrm{~V}$ and then amplified to $30 \mathrm{kV}[9-11,16]$. A detailed diagram of the DBD-plasma reactor was presented in Figure 2, indicating the different experimental parts used to create the plasma. The air stream at the outlet of the DBD-plasma reactor, under goes a second oxidation step. The fixed-bed reactor consists of a Pyrex glass of $30 \mathrm{~mm}$ as internal diameter and $15 \mathrm{~cm}$ length. At the bottom of the tube, sintered glass is placed to hold the catalyst, and the catalyst weight is varied between 20 and $60 \mathrm{~g}$ and the height of the catalytic bed varied from 5 to $15 \mathrm{~cm}$ (see Fig. 1). 


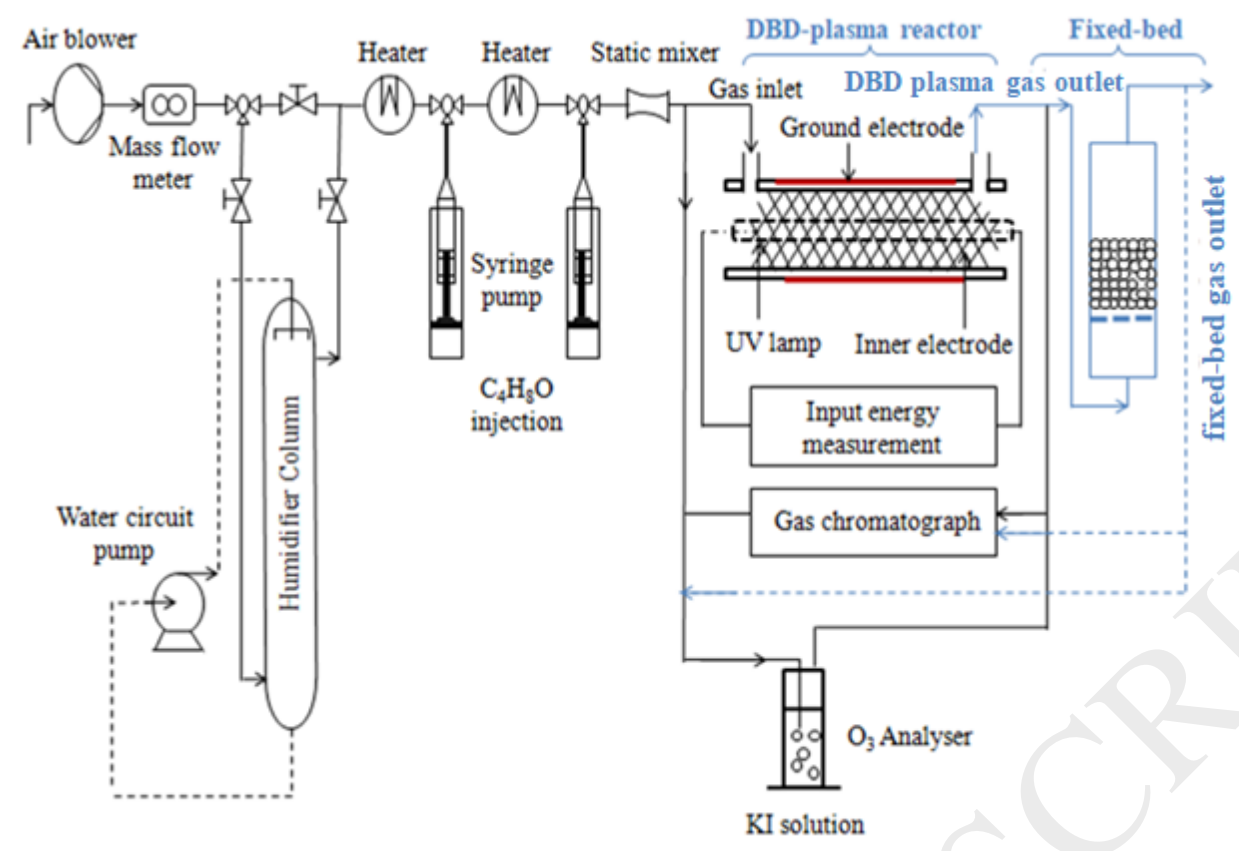

Figure 1.Schematic of the experimental setup: annular and fixed-bed reactors.

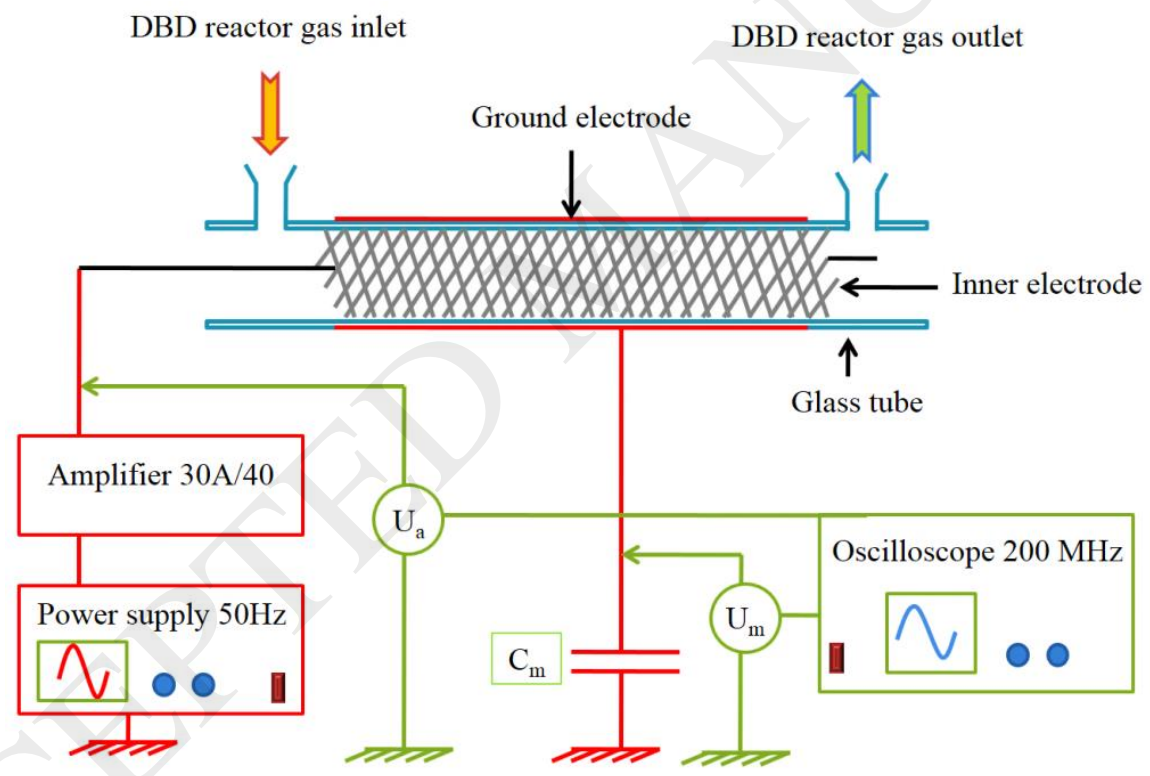

Figure 2. General electric diagram of the DBD-plasma reactor.

\subsection{Pollutants and Zeolites}

Butyraldehyde $\left(\mathrm{C}_{4} \mathrm{H}_{8} \mathrm{O}, 99.9 \%\right.$ purity) was purchased from Sigma Aldrich. It is injected continuously in liquid state by means of a programmable syringe pump system (KdScientific Model 100). A static mixer upstream ensures a good mixture of the gaseous effluent. Three catalytic materials were tested, namely two types of commercial zeolites from TOSOH Corp Tokyo75 Japan with microporous structures 
(ZSM-5 and Mordenite) and $\gamma$-alumina with mesoporous structures from Alfa Aesar Company. The characteristics of the materials are presented in Table 2.

Table 2. Main characteristics of the zeolites and $\gamma$-alumina

\begin{tabular}{lccc}
\hline Type & ZSM-5 & Mordenite & $\gamma$-alumina \\
\hline Pore diameter $(\AA)$ & $(5,7 \times 5,3)+$ & $(6,6 \times 7)+$ & 150 \\
& $(5,1 \times 5.5)$ & $(3,5 \times 6,7)$ & \\
\hline Si $/ \mathrm{Al}(\mathrm{mol} / \mathrm{mol})$ & 1880 & 220 & 0 \\
\hline BET surface $\left(\mathrm{m}^{2} / \mathrm{g}\right)$ & 308 & 509 & 237 \\
\hline Pore volume $\left(\mathrm{cm}^{3} / \mathrm{g}\right)$ & 0,11 & 0,21 & 0,15 \\
\hline Binder type $(\%$ weight$)$ & Alumina $(20 \%)$ & Alumina $(20 \%)$ & - \\
\hline Pellet diameter $(\mathrm{mm})$ & 1,5 & 1,5 & 3 \\
\hline
\end{tabular}

\subsection{Analytical device}

The concentration of Butyraldehyde (BUTY) at the inlet/outlet of annular and fixedbed reactor was sampled manually with a $500 \mu \mathrm{L}$ syringe and analyzed by a gas chromatography (Fisons GC9000) equipped with a flame ionization detector (GCFID). The various intermediate by-products produced during the Butyraldehyde degradation were measured in a Gas Chromatograph-Mass Spectrometer (GC-MS) coupled to an infrared (IR) detector. The Ozone concentration at the outlet of annular and fixed-bed reactor was monitored by iodometric titration method. The outlet air stream (annular reactor and/or fixed-bed) is bubbled through a potassium iodide (KI) solution with $10^{-2} \mathrm{M}$ concentration until a yellow color emerges. The sample is then titrated with sodium thiosulfate solution $\left(\mathrm{Na}_{2} \mathrm{~S}_{2} \mathrm{O}_{3}\right)$ with $10^{-2} \mathrm{M}$ until a colorless solution is obtained [10]. The relative humidity in the air stream was controlled. All experiments were carried out at ambient conditions, atmospheric pressure and room temperature. The temperature and relative humidity $(\mathrm{RH})$ were determined using a specific sensor (Testo 445). An AXIS NOVA photoelectron spectrometer (Kratos Analytical, Manchester, UK) provided for with monochromatic AlKa (hv=1486.6 eV) anode. Binding energies (BE) were calibrated against the standard $\mathrm{C} 1 \mathrm{~s}$ binding energy at $284.6 \mathrm{eV}[19,20]$. A Multipak (version 9 software) using 70:30 Gaussian: Lorentzian peak shape and a Shirley background function were used for Spectra deconvolution [21]. 
Process performance was evaluated by measuring:

- Inlet $\left[\mathrm{C}_{4} \mathrm{H}_{8} \mathrm{O}\right.$ inlet $]$ and outlet $\left[\mathrm{C}_{4} \mathrm{H}_{8} \mathrm{O}_{\text {outlet }}\right.$ concentrations of $\mathrm{C}_{4} \mathrm{H}_{8} \mathrm{O}$

- Removal efficiency of $\mathrm{C}_{4} \mathrm{H}_{8} \mathrm{O}: \operatorname{RE}(\%)=\frac{\left(\left[\mathrm{C}_{4} \mathrm{H}_{8} \mathrm{O}\right]_{\text {inlet }}-\left[\mathrm{C}_{4} \mathrm{H}_{8} \mathrm{O}\right]_{\text {outlet }}\right) \times 100}{\left[\mathrm{C}_{4} \mathrm{H}_{8} \mathrm{O}_{\text {outlet }}\right]}$

- Specific input energy: $\operatorname{SIE}\left(\mathrm{J} \mathrm{L}^{-1}\right)=\frac{3600 * \mathrm{P}(\mathrm{W})}{\mathrm{Q}\left(\mathrm{m}^{3} \mathrm{~h}^{-1}\right) \times 1000}$

where $P$ is input power adjusted by changing the applied voltage $\left(U_{a}\right)$ and $Q$ is the flowrate.

- Selectivity of CO: $\quad \mathrm{SCO}(\%)=\frac{\left[\mathrm{CO}_{\text {outlet }}-[\mathrm{CO}]_{\text {inlet }}\right.}{4 \times \mathrm{RE}(\%) \times\left[\mathrm{C}_{4} \mathrm{H}_{8} \mathrm{O}\right]_{\text {in }}} * 10000$

- Selectivity of $\mathrm{CO}_{2}: \mathrm{SCO}_{2}(\%)=\frac{\left[\mathrm{CO}_{2}\right]_{\text {outlet }}-\left[\mathrm{CO}_{2}\right]_{\text {inlet }}}{4 \times \mathrm{RE}(\%) \times\left[\mathrm{C}_{4} \mathrm{H}_{8} \mathrm{O}\right]_{\text {inlet }}} * 10000$

\section{Results and discussion}

\subsection{Butyraldehyde and Ozone removal: Mordenite \& $\gamma$-alumina supports Vs ZSM-} 5

Figure 3 shows the concentrations of Butyraldehyde and Ozone within DBDplasma/fixed-bed reactor in processes mediated by ZSM-5, Mordenite and $\gamma$-alumina. Regarding Butyraldehyde degradation, it was observed that the outlet concentration of Butyraldehyde decreases from $60.75 \mathrm{mg} \mathrm{m}^{-3}$ (DBD-reactor gas outlet) to $41.23 \mathrm{mg} \mathrm{m}^{-3}$ (fixed-bed gas outlet), $51.92 \mathrm{mg} \mathrm{m}^{-3}$ (fixed-bed gas outlet) and $59.43 \mathrm{mg} \mathrm{m}^{-3}$ (fixed-bed gas outlet) when using ZSM-5, Mordenite and $\gamma$-alumina, respectively, for $\mathrm{C}_{4} \mathrm{H}_{8} \mathrm{O}$ inlet concentration of $100 \mathrm{mg} \mathrm{m}^{-3}$. A similar behavior was observed for ozone. The Ozone concentration decreases from $104.79 \mathrm{mg} \mathrm{m}^{-3}$ (DBD-reactor gas outlet) to $84.51 \mathrm{mg} \mathrm{m}^{-3}$ (ZSM-5), $88.73 \mathrm{mg} \mathrm{m}^{-3}$ (Mordenite) and $94.57 \mathrm{mg} \mathrm{m}^{-3}$ ( $\gamma$-alumina) with SIE of $8 \mathrm{JL}^{-1}$. When using $\gamma$-alumina, the presence of water vapor $(\mathrm{HR}=45 \%)$ inhibits the decomposition of ozone and therefore negatively influenced Butyraldehyde oxidation. A competition between water, Butyraldehyde and Ozone on the sites of adsorption of $\gamma$-alumina seems to be responsible for this observation [22]. Only $11 \%$ of the Butyraldehyde and $14 \%$ of Ozone was removed in the fixed-bed reactor. Roscoe et al. [23], by FTIR (Fourier Transform InfraRed) spectroscopy reported the high affinity of $\gamma$ alumina for water molecules at sites that may be involved in the decomposition of ozone [23]. As it is readily seen in Figure 3, ZSM-5 leads to highest Butyraldehyde degradation and Ozone oxidation. 


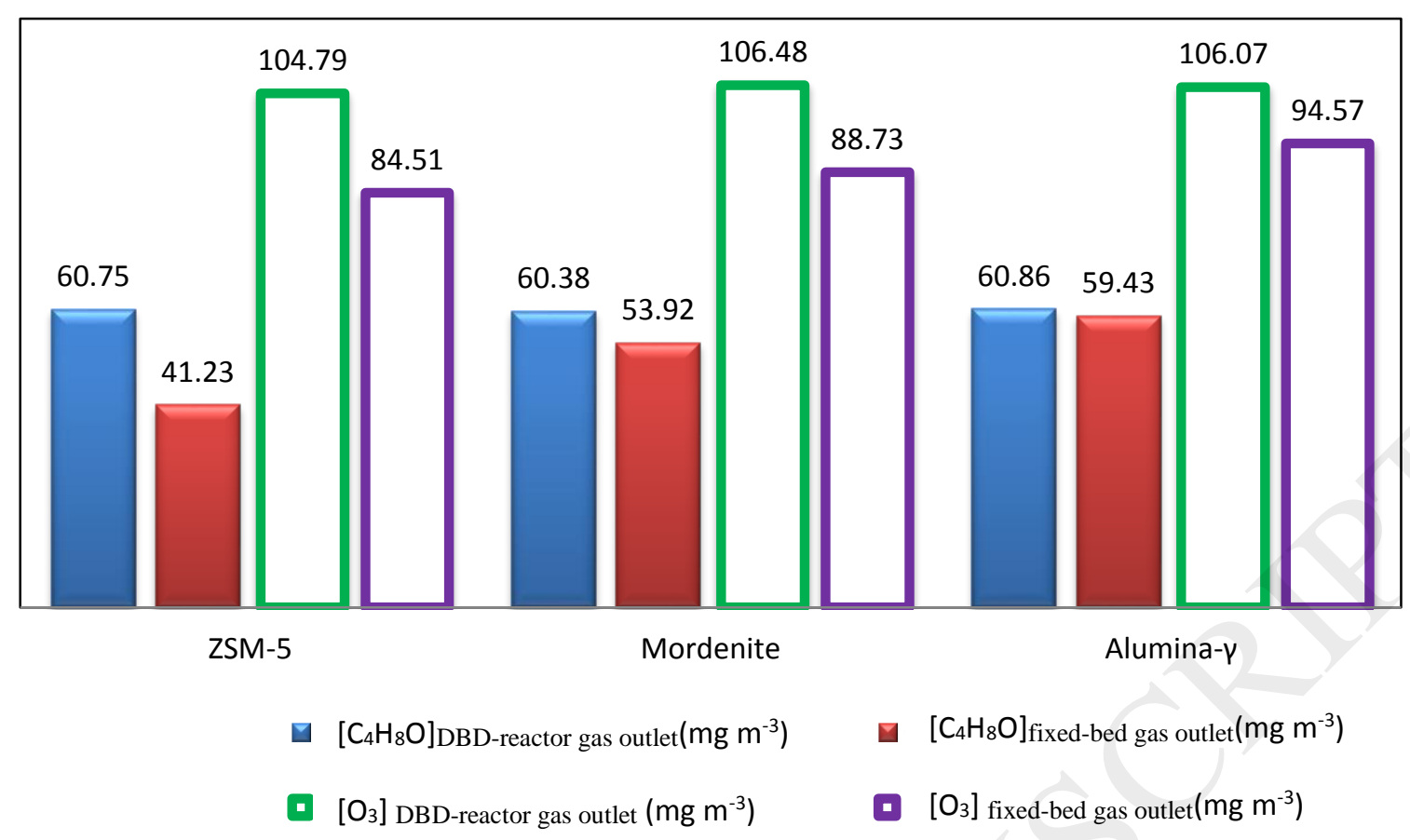

Figure 3. Ozone and Butyraldehyde concentration, at DBD-reactor outlet, under DBDplasma/fixed-bed system with three differents catalysts $\left[Q=1 \mathrm{~m}^{3} \mathrm{~h}^{-1}\right.$, SIE 1. $\left[\mathrm{C}_{4} \mathrm{H}_{8} \mathrm{O}\right]_{0}=100 \mathrm{mg} \mathrm{m}^{-3}$, catalyst $\left.=20 \mathrm{~g}, \mathrm{~T}=25^{\circ} \mathrm{C}, \mathrm{RH}=45 \%\right]$.

\subsection{Single Plasma and Catalytic Ozonation: case of ZSM-5}

The effects of three major operating parameters, namely: (i) plasma specific energy, (ii) initial Butyraldehyde concentration and (iii) relative humidity on Butyraldehyde degradation using ZSM-5 were monitored. The gas flow rate $\left(1 \mathrm{~m}^{3} \mathrm{~h}^{-1}\right)$ and the weight of the catalyst $(20 \mathrm{~g})$ have been fixed as constant for all the experiments.

\subsubsection{Effect of specific input energy}

Two experiments with specific input energy of $9 \mathrm{~J} \mathrm{~L}^{-1}$ and $18 \mathrm{~J} \mathrm{~L}^{-1}$ have been carried out under relative humidity of $5 \%$ and $100 \mathrm{mg} \mathrm{m}^{-3}$ of Butyraldehyde. The evolutions of Butyraldehyde concentration at the outlet of the first reactor (DBD- plasma reactor gas outlet) and the second reactor (fixed-bed gas outlet) for both SIE are reported in Figure 4. The Butyraldehyde oxidation is carried out for 8 hours. $\mathrm{C}_{4} \mathrm{H}_{8} \mathrm{O}$ oxidation was observed in DBD-plasma process and then moves through the catalytic bed for a second degradation. 


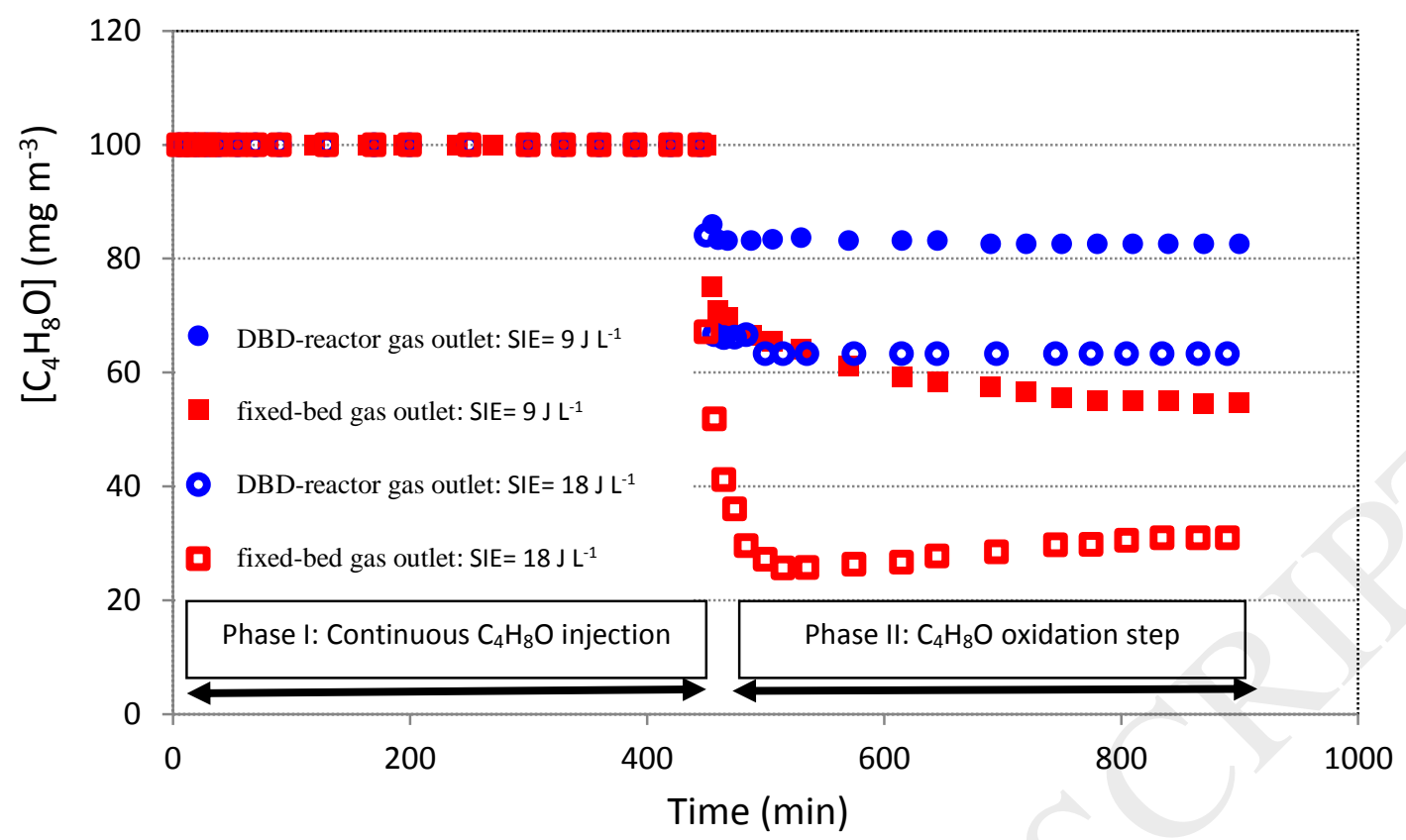

Figure 4. Variation of $\mathrm{C}_{4} \mathrm{H}_{8} \mathrm{O}$ outlet concentration as function of time with differents specific energy under DBD-plasma/fixed-bed system in the case of ZSM-5(Phase I: inlet $\mathrm{C}_{4} \mathrm{H}_{8} \mathrm{O}$ injection; Phase II: $\mathrm{C}_{4} \mathrm{H}_{8} \mathrm{O}$ oxidation step) $\left[\mathrm{Q}=1 \mathrm{~m}^{3} \mathrm{~h}^{-1}\right.$, SIEplasma $=18 \mathrm{JL}^{-1}$, [ZSM-5] $=20 \mathrm{~g}, \mathrm{~T}=25^{\circ} \mathrm{C}, \mathrm{HR}=5 \%$ ].

As it is readily seen from Figure4, the DBD-plasma process is more effective when high specific input energy is applied. At $18 \mathrm{~J} \mathrm{~L}^{-1}$, the degradation rate, by DBD-plasma, is around $37 \%$, thus $63.29 \mathrm{mg} \mathrm{m}^{-3}$ of Butyraldehyde is measured at the inlet of the fixed-bed. Interestingly, only $17 \%$ degradation is achieved with $9 \mathrm{~J} \mathrm{~L}^{-1}$ of SIE.

The concentration of Ozone and BUTY at the outlet of the DBD, fixed-bed reactor and the ratio between Ozone and Butyraldehyde have been determined during the oxidation phase and reported in Figure 5. An increase of specific input energy from 9 to $18 \mathrm{~J} \mathrm{~L}^{-1}$ enhanced the Ozone decomposition; at $18 \mathrm{~J} \mathrm{~L}^{-1}$, the ratio was about ten times higher than with SIE of $9 \mathrm{~J} \mathrm{~L}^{-1}$. The value of the ratio $\left(\mathrm{O}_{3} / \mathrm{BUTY}\right)$ at $9 \mathrm{~J} \mathrm{~L}^{-1}$ is 0.46 and it reaches 4.7 for $18 \mathrm{~J} \mathrm{~L}^{-1}$. The difference in the rate of Ozone decomposition between the two ratios suggests that all active sites of ZSM-5 are not fully occupied by Ozone at $9 \mathrm{~J} \mathrm{~L}^{-1}$. 


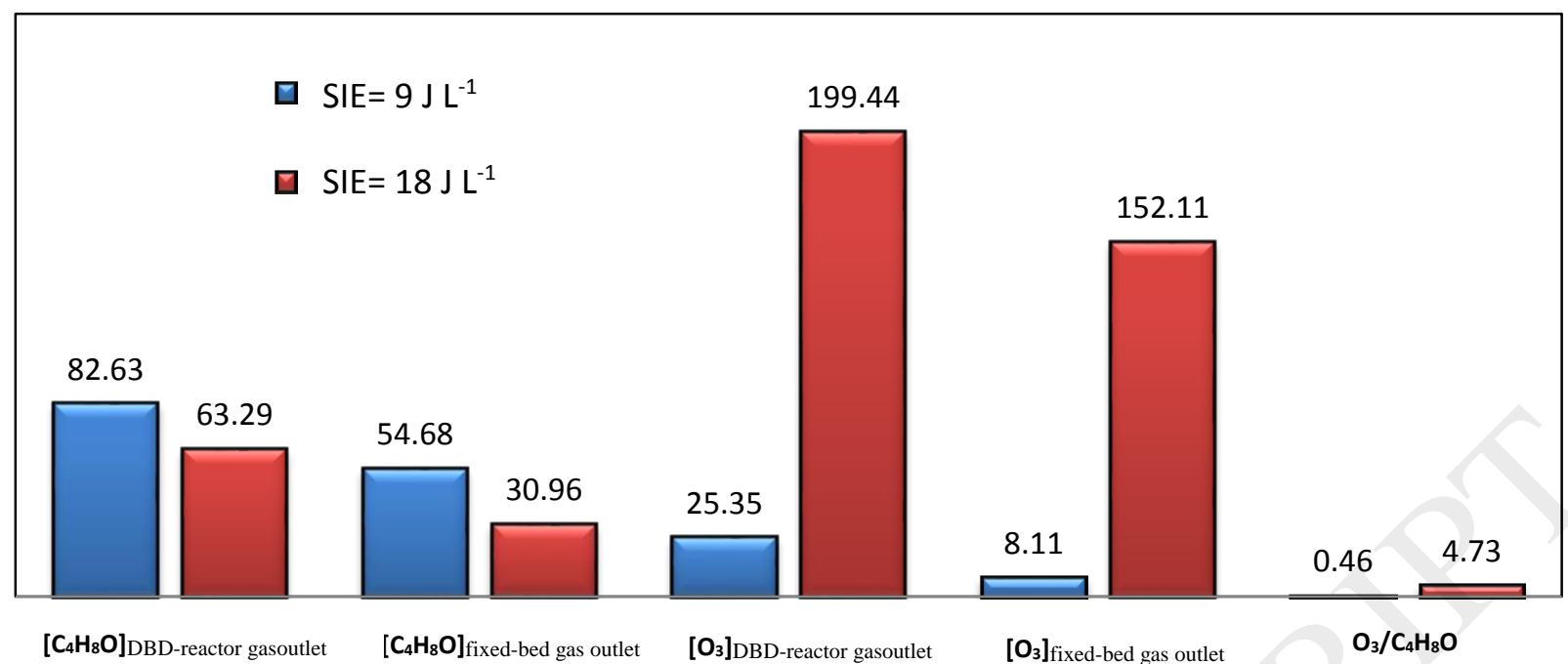

Figure 5. $\mathrm{C}_{4} \mathrm{H}_{8} \mathrm{O}$ and Ozone concentrations $\left(\mathrm{mg} \mathrm{m}^{-3}\right)$ in outlet DBD-reactor and outlet fixed-bed for two different specific energy $\left[\mathrm{Q}=1 \mathrm{~m}^{3} \mathrm{~h}^{-1},[Z S M-5]=20 \mathrm{~g}, \mathrm{~T}=25^{\circ} \mathrm{C}\right.$, $\mathrm{HR}=5 \%$.

\subsubsection{Effect of $\mathrm{C}_{4} \mathrm{H}_{8} \mathrm{O}$ concentration}

At fixed SIE of $18 \mathrm{JL}^{-1}$, the effect of BUTY concentration on degradation rate and ozone consumption at the fixed bed reactor has been investigated. The BUTY concentrations are: (i) $100 \mathrm{mg} \mathrm{m}^{-3}$ and (ii) $200 \mathrm{mg} \mathrm{m}^{-3}$ with a continuous flowrate of 1 $\mathrm{m}^{3} \mathrm{~h}^{-1}$ and $\mathrm{RH}=5 \%$. The inlet concentration of BUTY significantly influences the ratio of $\mathrm{O}_{3} / \mathrm{C}_{4} \mathrm{H}_{8} \mathrm{O}$ ). Experimental data for Ozone and Butyraldehyde consumption during $\mathrm{C}_{4} \mathrm{H}_{8} \mathrm{O}$ degradation when applying DBD-plasma and post-plasma (fixed-bed) treatments are summarized in Figure 6. Regarding the influence of inlet concentration, a result shows that the ratio $\left(\mathrm{O}_{3} / \mathrm{C}_{4} \mathrm{H}_{8} \mathrm{O}\right)$ was significantly affected by increasing $\mathrm{C}_{4} \mathrm{H}_{8} \mathrm{O}$ concentration. 


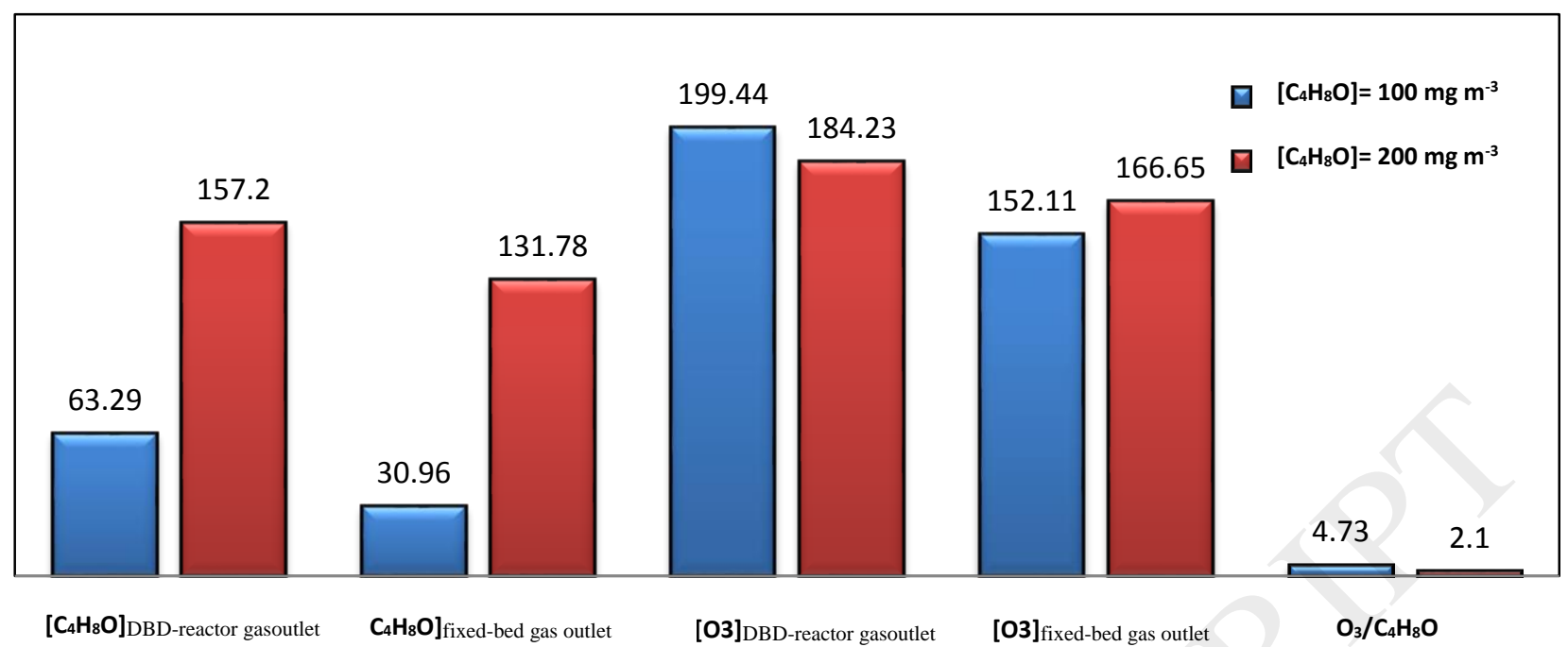

Figure 6. $\mathrm{C}_{4} \mathrm{H}_{8} \mathrm{O}$ and Ozone concentrations $\left(\mathrm{mg} \mathrm{m}^{-3}\right)$ in DBD-reactor outlet and fixedbed outlet for two differents inlet concentrations $\left[Q=1 \mathrm{~m}^{3} \mathrm{~h}^{-1}, \mathrm{SIE}_{\mathrm{plasma}}=18 \mathrm{JL}^{-1}\right.$,

$$
\left.[Z S M-5]=20 \mathrm{~g}, \mathrm{~T}=25^{\circ} \mathrm{C}, \mathrm{HR}=5 \%\right]
$$

For $100 \mathrm{mg} \mathrm{m}^{-3}$ of Butyraldehyde at the inlet of (DBD-plasma/fixed-bed) system, the ratio $\left(\mathrm{O}_{3} / \mathrm{BUTY}\right)$ reaches 4.7 whereas for high concentration $\left(\left[\mathrm{C}_{4} \mathrm{H}_{8} \mathrm{O}\right]=200 \mathrm{mg} \mathrm{m}^{-3}\right)$; the ratio is 2.1 .

The removal efficiency of $\mathrm{C}_{4} \mathrm{H}_{8} \mathrm{O}$ significantly decreased from $51.07 \%$, at $\left[\mathrm{C}_{4} \mathrm{H}_{8} \mathrm{O}\right]=$ $100 \mathrm{mg} \mathrm{m}^{-3}$, to $16.11 \%$ for $\left[\mathrm{C}_{4} \mathrm{H}_{8} \mathrm{O}\right]=200 \mathrm{mg} \mathrm{m}^{-3}$ (Fig.6). The abatement of Butyraldehyde mediated by the DBD-plasma process as well as on fixed-bed reactor is higher at a lower initial concentration. It appears that for $\mathrm{C}_{4} \mathrm{H}_{8} \mathrm{O}$ inlet concentration of $200 \mathrm{mg} \mathrm{m}^{-3}$, the air flow is fairly saturated with Butyraldehyde, which limits the access of Ozone molecules to the micropores of ZSM-5, thus preventing its decomposition. The increase in the amount of Butyraldehyde causes a significant decrease of Ozone and Butyraldehyde. Thus, Ozone cannot be adsorbed on active sites and prevents the reactive sites to intervene in catalytic oxidation. Ozone contributes to oxidize Butyraldehyde already adsorbed on the zeolite and additionally, a part of the ozone is consumed to generate radicals on the free sites. Ozone decomposition occurs at the Lewis sites of zeolite, to produce atomic oxygen, peroxide ions and hydroxyl-radicals according to Eqs. (5-7) [22], to oxidize the adsorbed Butyraldehyde. 


$$
\begin{aligned}
& \mathrm{O}_{3}+\mathrm{Z}-\mathrm{Al} \longrightarrow \mathrm{Z}-\mathrm{Al} \ldots \mathrm{O}+\mathrm{O}_{2} \text { (5) } \\
& \mathrm{Z}-\mathrm{Al} \ldots \mathrm{O}+\mathrm{O}_{3} \longrightarrow \mathrm{Z}-\mathrm{Al} \ldots \mathrm{O}_{2}+\mathrm{O}_{2} \text { (6) } \\
& \mathrm{Z}-\mathrm{Al} \ldots \mathrm{O}_{2} \longrightarrow \mathrm{Z}-\mathrm{Al}+\mathrm{O}_{2}
\end{aligned}
$$

\subsubsection{Effect of humidity}

The humidity is inevitably present in the environment, thus the study of the effect of humidity on BUTY removal and Ozone decomposition were monitored in a humid environment. Three experiments, with ZSM-5 catalyst, have been carried out with relative humidity $(\mathrm{RH})$ of $5,45 \%$ and $90 \%$. The optimized experimental conditions used during $\mathrm{C}_{4} \mathrm{H}_{8} \mathrm{O}$ degradation are summarized in Table 3.

Table 3. Experimental conditions selected for $\mathrm{C}_{4} \mathrm{H}_{8} \mathrm{O}$ oxidation under (DBDplasma/fixed-bed) system

\begin{tabular}{ccccc}
\hline Parameter & Qair & {$\left[\mathrm{C}_{4} \mathrm{H}_{8} \mathrm{O}\right] 0$} & SIE $]_{0}$ plasma & W ZSM-5 \\
\hline Value & $1 \mathrm{~m}^{3} \mathrm{~h}^{-1}$ & $100 \mathrm{mg} \mathrm{m}^{-3}$ & $18 \mathrm{~J} \mathrm{~L}^{-1}$ & $20 \mathrm{~g}$ \\
\hline
\end{tabular}

Experimental results of Ozone and Butyraldehyde consumption rates for $\mathrm{C}_{4} \mathrm{H}_{8} \mathrm{O}$ degradation by DBD-plasma and post-plasma treatment under different humidity levels are presented in Figure 6 . The results show that the variation of $\mathrm{RH}$ causes a significant variation in terms of Butyraldehyde oxidation on DBD-plasma reactor. Indeed, a good removal efficiency is reached in the case of medium humidity of $\mathrm{RH}=45 \%$. However, it is observed that the increase in moisture significantly decreased the Ozone production, in agreement with references [10, 11, 16, 20]. Figure 7 illustrates the decrease of $\mathrm{C}_{4} \mathrm{H}_{8} \mathrm{O}$ degradation efficiency during the catalytic oxidation processes. 


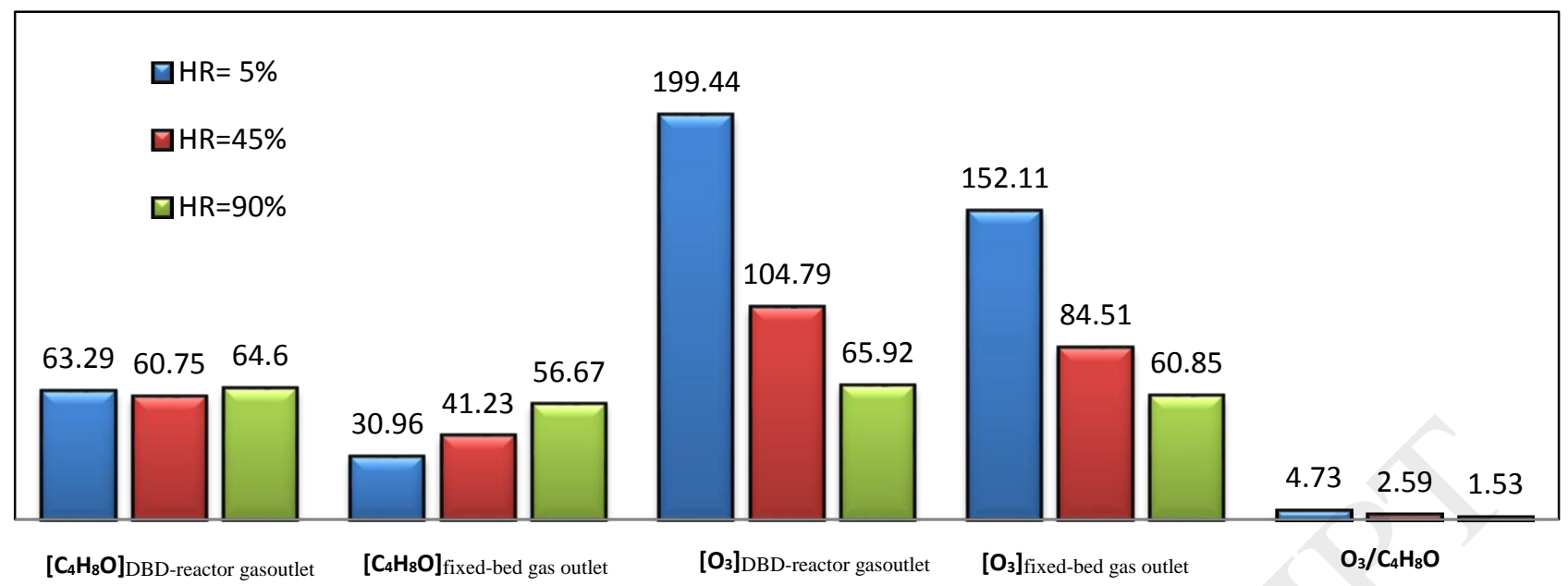

Figure 7. $\mathrm{C}_{4} \mathrm{H}_{8} \mathrm{O}$ and Ozone concentrations $\left(\mathrm{mg} \mathrm{m}^{-3}\right)$ in the outlet of DBD-reactor and outlet of fixed-bed with differents humidity $\left(Q=1 \mathrm{~m}^{3} \mathrm{~h}^{-1}, \mathrm{SIE}\right.$ plasma $=18 \mathrm{JL}^{-1},[Z S M-5]=20$

$$
g, \mathrm{~T}=25^{\circ} \mathrm{C}, \mathrm{HR}=5 \% \text { ). }
$$

The influence of relative humidity on Butyraldehyde degradation under catalytic oxidation was also monitored. By increasing the relative humidity in the air stream, a drop in consumption rates of the residual pollutants, namely $\mathrm{O}_{3}$ and $\mathrm{C}_{4} \mathrm{H}_{8} \mathrm{O}$, is observed. This was due to the effect of water molecules and Ozone adsorbed on the active sites of ZSM-5. Ozone will undergo a lower decomposition, which lead to a decrease in the performance of Butyraldehyde degradation.

\subsubsection{Effect of the catalyst dosage}

The influence of weight of the catalyst ZSM-5 on BUTY and Ozone removal is reported in this section. Figure8 shows the removal efficiency of BUTY under (DBDplasma/fixed-bed) system for two catalytic bed presenting different heights. It was observed that the increase in catalyst bed increased the BUTY removal efficiency. It can be seen that at $15 \mathrm{~cm}$, i.e. $60 \mathrm{~g}$ of ZSM-5, Ozone concentration measured at the outlet of (DBD-plasma/fixed-bed) system is practically zero $\left(\left[\mathrm{O}_{3}\right]=0.51 \mathrm{mg} \mathrm{m}^{-3}\right)$. In addition, BUTY consumption rate consumption rate was higher compared to catalytic beds $5 \mathrm{~cm}$ high. A higher catalyst height provides a reaction medium enhancing the Ozone decomposition 


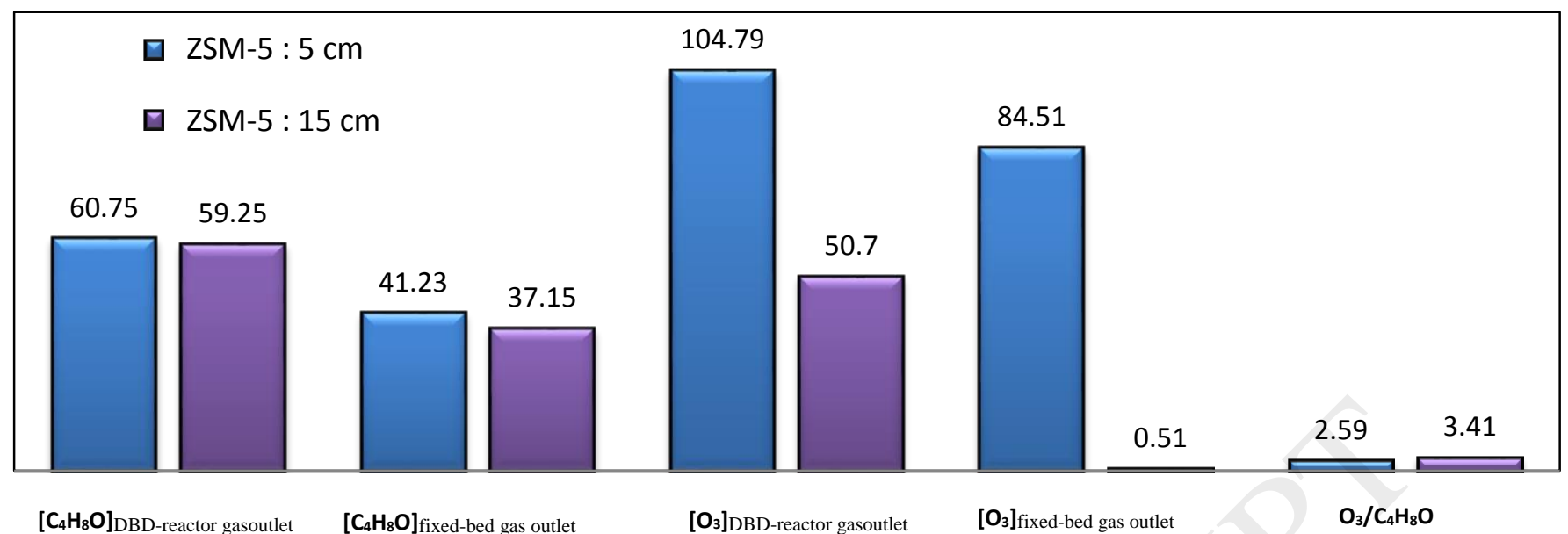

Figure 8. $\mathrm{C}_{4} \mathrm{H}_{8} \mathrm{O}$ and Ozone concentrations $\left(\mathrm{mg} \mathrm{m}^{-3}\right)$ in the outlet of DBD-reactor and outlet of fixed-bed for two differents heights $\left[Q=1 \mathrm{~m}^{3} \mathrm{~h}^{-1}\right.$, SIE

$$
5]=20 \mathrm{~g}, \mathrm{~T}=25^{\circ} \mathrm{C}, \mathrm{HR}=5 \% \text {. }
$$

\subsection{Effect of combined Plasma/Photocatalysis system and Catalytic Ozonation on Ozone removal and Butyraldehyde oxidation}

Process performance (UV-lamp/DBD-plasma/fixed-bed) was monitored during the photocatalysis $\left(\mathrm{TiO}_{2} / \mathrm{UV}\right.$-lamp) and DBD-plasma process for Butyraldehyde degradation. For this purpose, the UV lamp within DBD-plasma reactor was applied during the 8 hour runs. Coupling plasma technologies with photocatalysis for Butyraldehyde degradation was reported by our laboratory [24,16]. The association of both technologies in the same process led to synergistic effects improving the efficiency of VOCs removal [23, 25-27-30]. In order to approach the conditions of the industrial application of this process. Processes reported the coupling of DBD-plasma with photocatalysis $\left(\mathrm{TiO}_{2} / \mathrm{UV}\right.$-lamp) under humid conditions $(\mathrm{HR}=45 \%)$ applying continuous flow of $1 \mathrm{~m}^{3} \mathrm{~h}^{-1}$ and $100 \mathrm{mg} \mathrm{m}^{-3}$ of Butyraldehyde. The catalytic bed downstream of (UV-lamp/DBD-plasma) process was loaded with $60 \mathrm{~g}$ of ZSM-5 already saturated with Butyraldehyde. $\mathrm{C}_{4} \mathrm{H}_{8} \mathrm{O}$ adsorption step was realized on batch reactor (Pyrex 1L) and after reaching the adsorption equilibrium. The catalysts were then placed in the fixed-bed reactor. The results (Fig.9) show that the amount of Ozone at the outlet of fixed-bed is low and almost zero that is total consumption of ozone was observed on of ZSM-5. In addition, a more effective degradation is observed for Butyraldehyde. The catalytic bed allows complete decomposition of Ozone and good degradation of Butyraldehyde. Ozone concentration at the outlet of 
(UV-lamp/DBD-plasma/fixed-bed) was around $0.68 \mathrm{mg} \mathrm{m}^{-3}$ and the rate of Butyraldehyde removal efficiency reached $79.8 \%$.

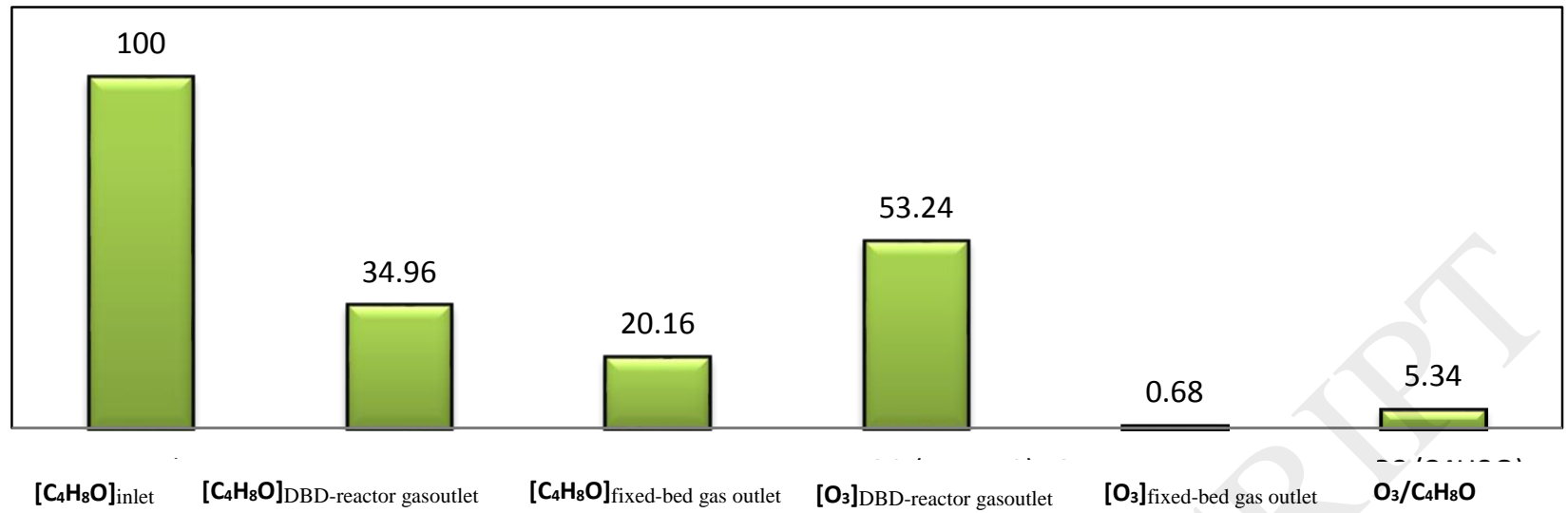

Figure 9. Variation of $\mathrm{C}_{4} \mathrm{H}_{8} \mathrm{O}$ concentration $\left(\mathrm{mg} \mathrm{m}^{-3}\right)$ and Ozone formation $\left(\mathrm{mg} \mathrm{m}^{-3}\right)$ under UV-lamp/DBD-plasma/fixed-bed system for ZSM-5 $\left[\mathrm{Q}=1 \mathrm{~m}^{3} \mathrm{~h}^{-1}, \mathrm{SIE}_{\text {plasma }}=18\right.$

$$
\left.\mathrm{JL}^{-1},[\mathrm{ZSM}-5]=20 \mathrm{~g}, \mathrm{~T}=25^{\circ} \mathrm{C}, \mathrm{HR}=5 \%\right] \text {. }
$$

\subsection{Pollutantmineralization ( $\mathrm{CO}$ and $\mathrm{CO}_{2}$ selectivity's) and by-products identification}

The evolution of $\mathrm{CO}$ and $\mathrm{CO}_{2}$ selectivity and Ozone concentration at the outlet of DBDplasma/photocatalytic reactor and fixed-bed are presented in Figure 10. An increase in mineralization rate and a total consumption of Ozone is observed (Fig. 10) during the catalytic oxidation of Butyraldehyde. This observation shows that humidity enhances the decomposition of Ozone on ZSM-5 into hydroxyl radicals and consequently favors mineralization [31-34]. Indeed, $\mathrm{CO}_{2}$ reached the highest selectivity at the outlet of fixed-bed reactor with a rate of $81.61 \%$ against $40.7 \%$ for DBD-plasma/photocatalytic reactor and a higher performance in Ozone removal on ZSM-5. Brodu et al., obtained similar results for the toluene degradation $[22,28]$ under catalytic ozonation. The CO, selectivity measured either at the outlet of DBD-plasma/photocatalytic reactor or at the outlet of fixed-bed reactor remained constant around 5\% (see Fig. 10). 


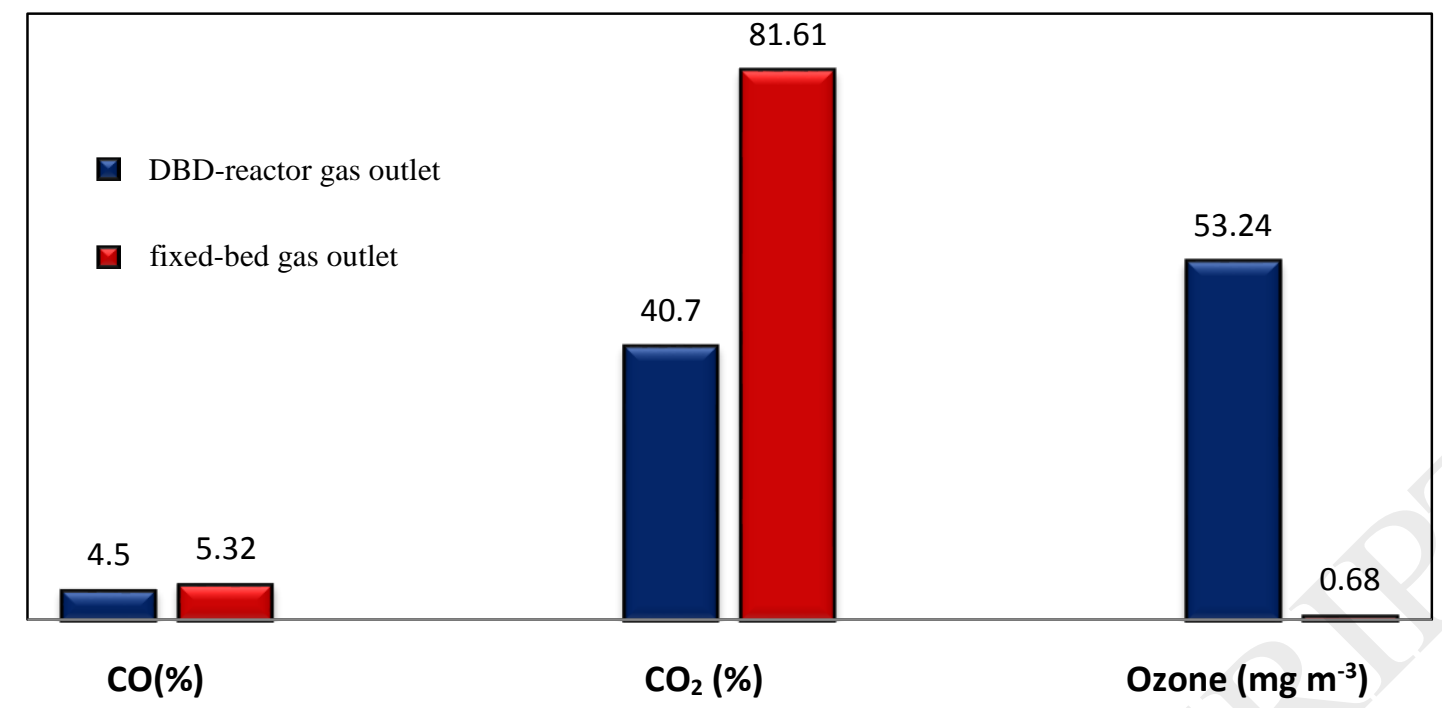

Figure 10. $\mathrm{CO}_{x}$ selectivity (\%) and ozone concentration in the outlet of DBD-reactor and outlet of fixed-bed $\left[\mathrm{Q}=1 \mathrm{~m}^{3} \mathrm{~h}^{-1},\left[\mathrm{C}_{4} \mathrm{H}_{8} \mathrm{O}\right]=100 \mathrm{mg} \mathrm{m}^{-3}\right.$, [ZSM-5]=20 g, SIEplasma=18

$$
\left.\mathrm{JL}^{-1}, \mathrm{~T}=25^{\circ} \mathrm{C}, \mathrm{HR}=45 \%\right] \text {. }
$$

The by-products generated under DBD-plasma/photocatalytic reactor (DBDplasma/UV-lamp) and fixed-bed reactor were monitored by Gas Chromatography coupled to Mass Spectrometry (GC-MS). All samples are concentrated on a Carbotrap $(25 \mathrm{ml})$ and then removed by thermal desorption unit coupled with GC-MS. The chromatograms are shown in Figure11. The intermediate by-products detected other than $\mathrm{CO}_{2}$ were: acetone $\left(\mathrm{C}_{3} \mathrm{H}_{5} \mathrm{O}\right)$, acetaldehyde $\left(\mathrm{C}_{2} \mathrm{H}_{4} \mathrm{O}\right)$, acetic acid $\left(\mathrm{C}_{2} \mathrm{H}_{4} \mathrm{O}_{2}\right)$, propionic acid $\left(\mathrm{C}_{3} \mathrm{H}_{6} \mathrm{O}_{2}\right)$ and butanoic acid $\left(\mathrm{C}_{4} \mathrm{H}_{8} \mathrm{O}_{2}\right)$.

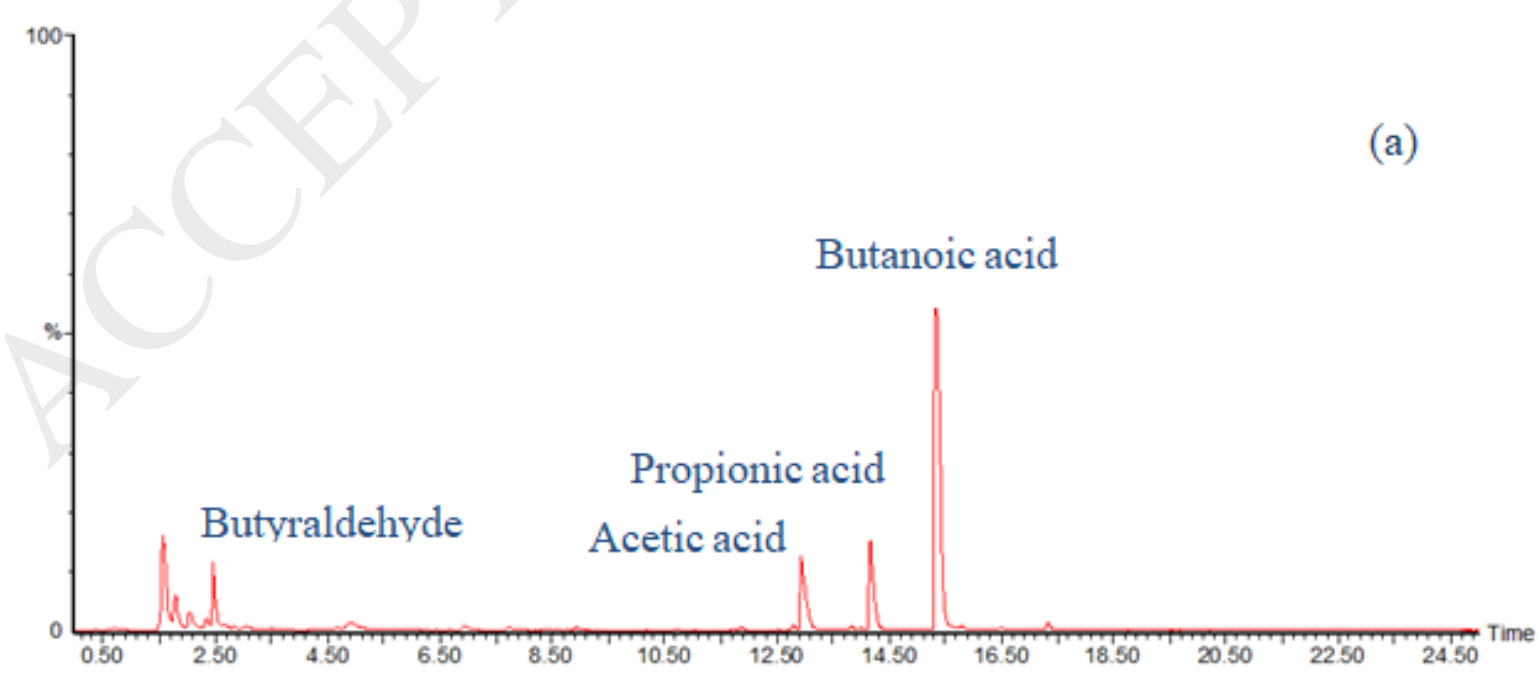




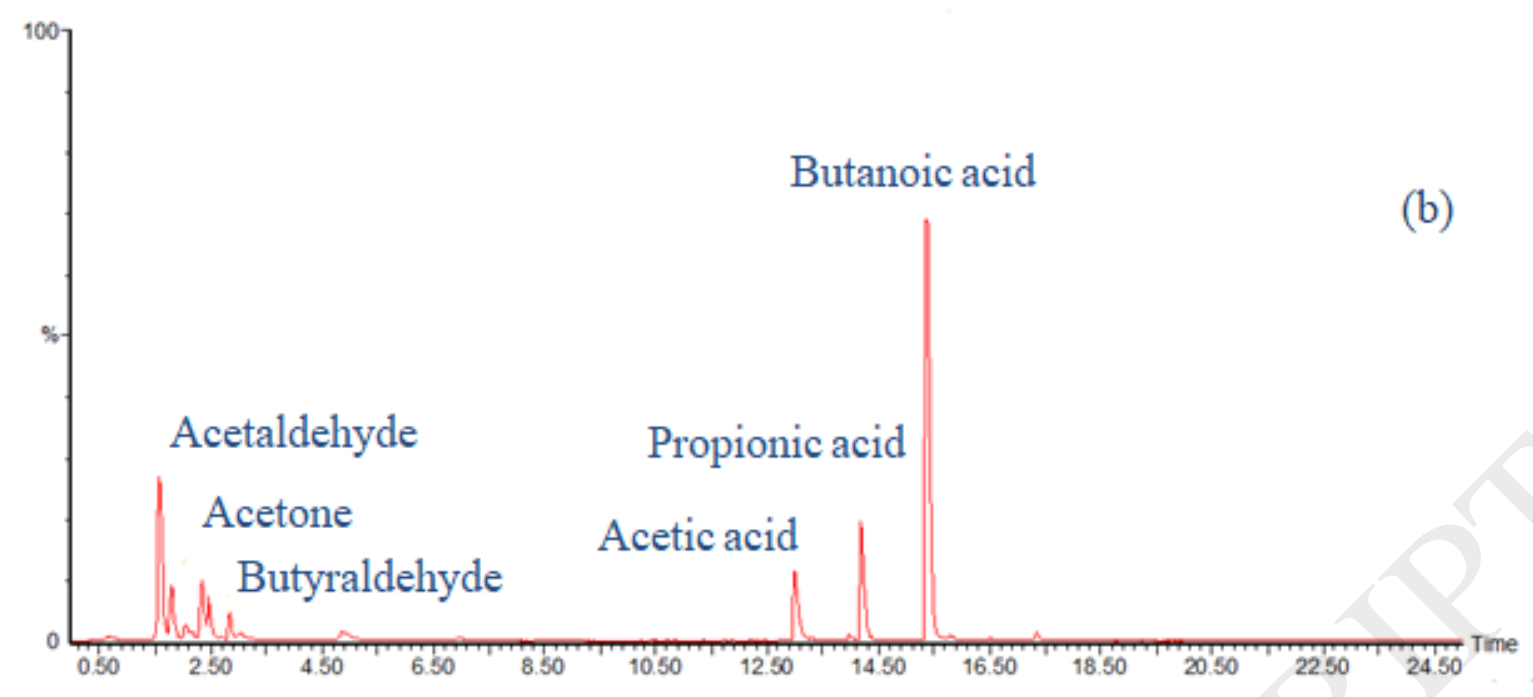

Figure 11. Intermediate by-products identified by GC-MS for $\mathrm{C}_{4} \mathrm{H}_{8} \mathrm{O}$ degradation when applying DBD-plasma/photocatalysis and fixed-bed reactor: (a) DBD-reactor gas outlet: DBD-plasma/photocatalysis, (b) fixed-bed gas outlet.

The surface atomic concentrations of elements before and after the Ozone and residual VOC decomposition were investigated by XPS. Table 4 shows the zeolite surface atomic concentration percentage after the effect of the combined catalytic processes [25]. During the catalytic ozonation, the carboxylic acid intermediates were partly mineralized to $\mathrm{CO}_{2}$ and $\mathrm{H}_{2} \mathrm{O}$ and partly increased the $\mathrm{C}$ 1s concentration on the catalysts surface as seen in Table 4 from 9.69 to $15.04 \%$ during Butyraldehyde degradation in the presence of Ozone [16, 20,36-40].

Table 4.Surface atomic percentage of elements as determined by XPS.

\begin{tabular}{lccccc}
\hline & C1s & N1s & O1s & Al2p & Si2p \\
\hline Before & 9.69 & 0.45 & 61.37 & 22.89 & 5.61 \\
\hline After & 15.04 & 0.1 & 58.82 & 21.89 & 4.14 \\
\hline
\end{tabular}

Figure 12 shows the oxidative states of the elements reported in Table 2 before and after the pollutant removal under light. Before usage of the ZSM- 5 beds, the O1s showed peaks at 534.6 and $533 \mathrm{eV}$ reflecting O-Si and O-Al bindings. After usage, ZSM- 5 shows the presence of $\mathrm{H}_{2} \mathrm{O}$ [41] and $\mathrm{O}_{2}$ [42], which can be attributed to: (i) the attributed humidity during the pollutant removal, (ii) the removal/mineralization of the pollutants generating $\mathrm{CO}_{2}$ and $\mathrm{H}_{2} \mathrm{O}$, and (iii) the contact with air after the reaction 
when recovering the ZSM-5 beds. This later factor did not significantly affect the nonused beds, which favors the first two arguments. Surprisingly, the signal related to AlO was not detected at this stage. Before use, ZSM- 5 presented partially oxidized AI2p. However, after exposure to the photocatalytic oxidation and the generated $\mathrm{O}_{3}$, the Al2p shows peak at 77.2 reflecting totally oxidized $\mathrm{Al}$, mainly $\mathrm{Al}_{2} \mathrm{O}_{3}$. When exposed to oxygen, the Al metal surface oxidizes reaching saturation, while the subsurface may stay showing metallic Al, with a characteristic Al2p signal at $\sim 76 \mathrm{eV}$. The saturated interface reacts further with oxygen, and eventually the bulk metal is transformed into oxide at room temperature. It is concluded that molecular oxygen does not dissociate on the oxide while atomic oxygen is still capable of adsorbing and diffusing into the bulk as recently reported by Cakir et al. [43]. The same authors showed that atomic oxygen adsorption broadens the O2p valence band. All photoemission peaks underwent a rigid shift to low binding energies, which is consistent with the formation of $\mathrm{O}_{2}{ }^{-}$surface atoms [43]. The deconvolution of $\mathrm{Si} i \mathrm{p}$ spectra showed the presence of $\mathrm{SiO}_{2}\left(\mathrm{Al}_{2} \mathrm{O}_{3}\right)$ n [44] and $\mathrm{Si}-\mathrm{C}[45]$.

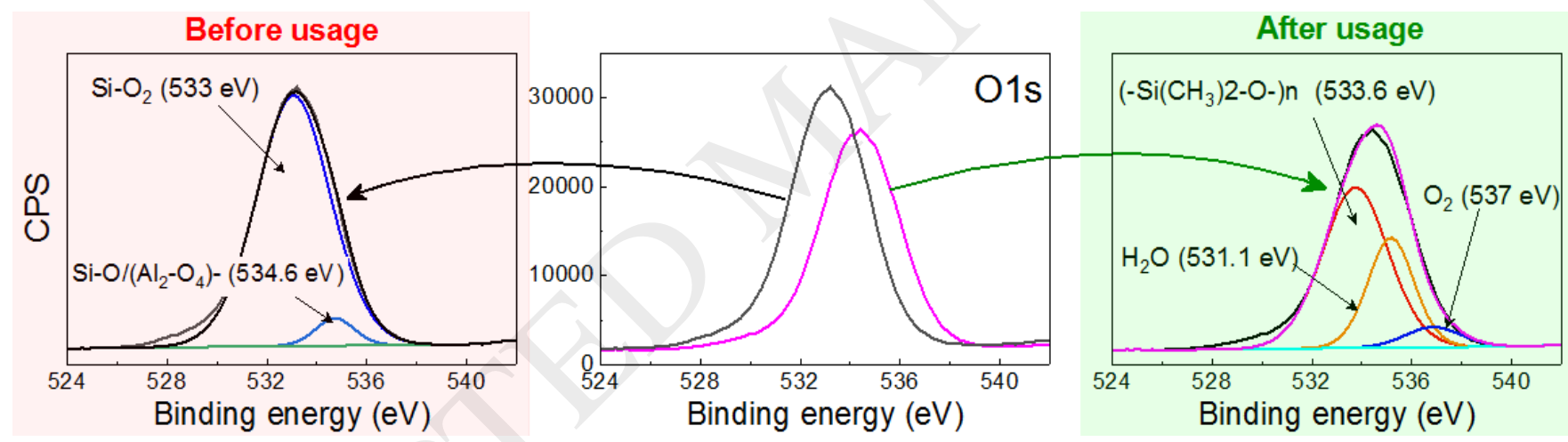

Figure 12a. XPS deconvolution of O1s in the ZSM- 5 catalytic beds before and after use in BUTY removal in the DBD-plasma/photocatalysis/catalytic ozonation system.

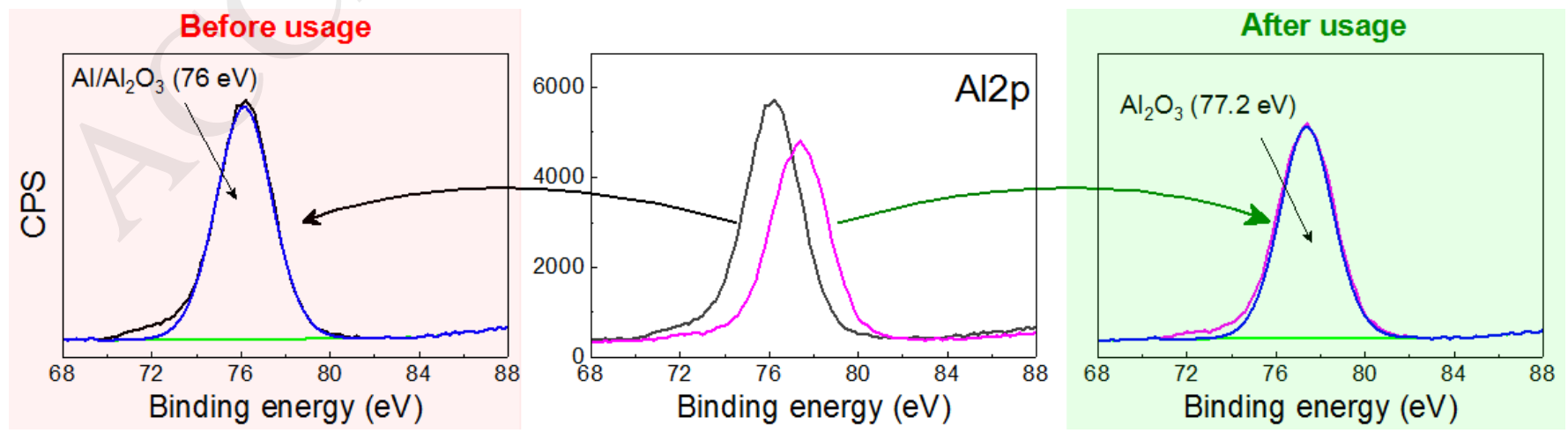


Figure 12b. XPS deconvolution of Al2p in the ZSM- 5 catalytic beds before and after use in BUTY removal in the DBD-plasma/photocatalysis/catalytic ozonation system.

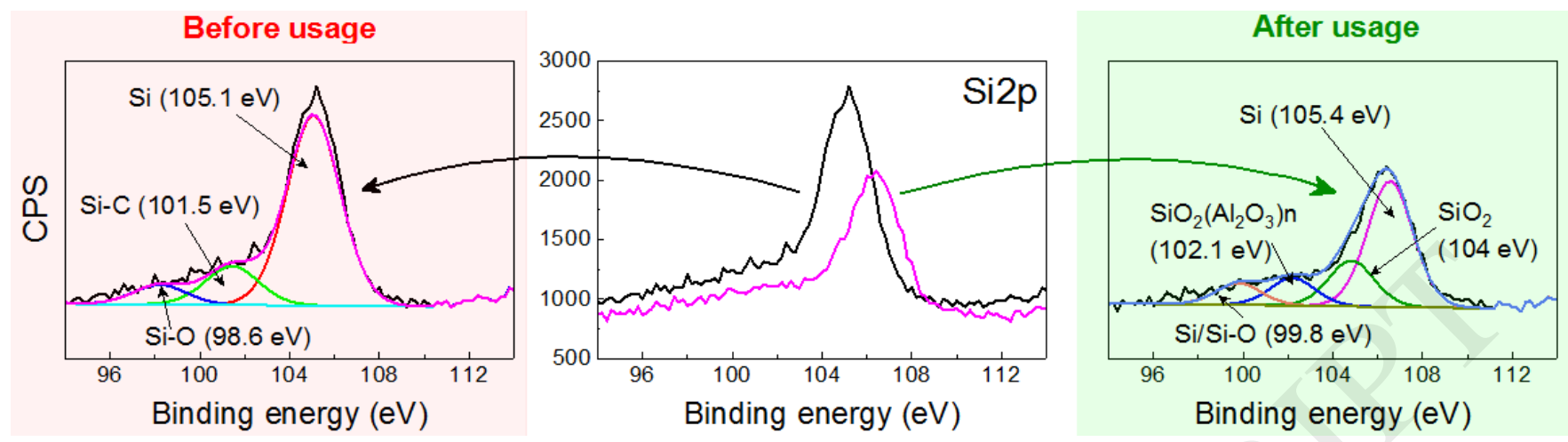

Figure 12c. XPS deconvolution of Si2p in the ZSM-5 catalytic beds before and after use in BUTY removal in the DBD-plasma/photocatalysis/catalytic ozonation system.

The peaks shifts observed in Figure 12 ( $a, b$ and $c$ ) after the ZSM-5 usage in the catalytic removal of BUTY can be due to the oxidative states of the elements under light. The observed changes in the peaks intensities and shifts in the binding energies $(\mathrm{BE})$ of $\mathrm{O} 1 \mathrm{~s}, \mathrm{Al} 2 \mathrm{p}$ and Si2p provide the evidence for redox reactions taking place during the pollutant degradation time. This is related to the relative sensitivity factors of each element and the observed intensities of all elements on the catalyst surface. It is worth to mention that the peaks intensities depend on the X-ray emission, charge neutralization, signal acquisition resolution and the samples themselves [16,39].

The mechanism for $\mathrm{C}_{4} \mathrm{H}_{8} \mathrm{O}$ removal when applying simultaneously DBDplasma/photocatalysis/catalytic ozonation processes is suggested in Figure $13 . \mathrm{C}_{4} \mathrm{H}_{8} \mathrm{O}$ and $\mathrm{O}_{3}$ suggested to be adsorbed on the zeolites surface promoting a surface reaction where $\mathrm{O}_{3}$ is decomposed into surface active oxygen species/radicals reacting with Butyraldehyde [38, 39]. In our previous studies [16, 25] we reported on the degradation of air pollutants by coupling DBD-plasma and photocatalysis without catalytic ozonation using zeolites. These previous studies showed that the degradation of Butyraldehyde is the result of its oxidation by the photogenerated reactive oxygen species (ROS) created by plasma/photocatalysis (atomic oxygen, peroxide ions and hydroxyl radicals). The major by products were acetic acid $\left(\mathrm{C}_{2} \mathrm{H}_{4} \mathrm{O}_{2}\right)$, propionic acid $\left(\mathrm{C}_{3} \mathrm{H}_{6} \mathrm{O}_{2}\right)$ and butanoic acid $\left(\mathrm{C}_{4} \mathrm{H}_{8} \mathrm{O}_{2}\right)$. In this study, when we added the zeolite fixedbed reactor at the outlet of DBD-plasma /photocatalysis reactor, the outcomes show that the amount of residual Butyraldehyde decreased at the outlet of the fixed-bed 
reactor and the amount of the same by-products increased (Fig.11). These results show that a similar mechanism occurs when adding the zeolite fixed-bed reactor i.e. the generation of more ROS due to the contact of the Ozone (coming from plasma/photocatalysis reactor) with the active surface sites of the zeolites and the oxidation of Butyraldehyde in the fixed-bed with the ROS.

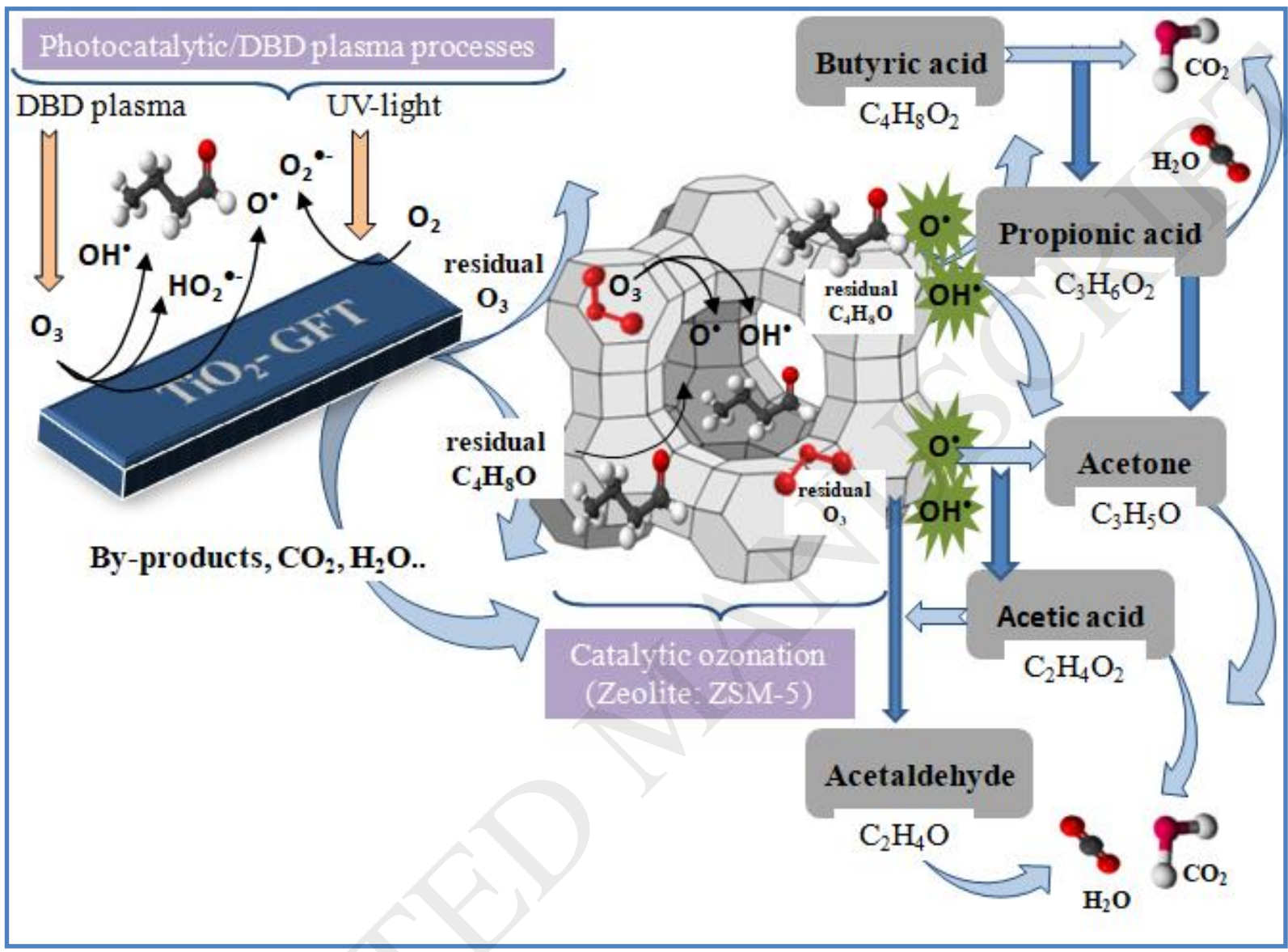

Figure13. Suggested mechanism for Butyraldehyde removal under simultaneous DBD-plasma/photocatalysis/catalytic ozonation.

\section{Conclusion}

Butyraldehyde degradation in a DBD-photocatalytic reactor by catalytic oxidation (on fixed-bed reactor) on ZSM-5, Mordenite and $\gamma$-alumina was reported. In this study, we show that by adding zeolite fixed-bed reactor to the plasma/photocatalysis reactor, we were able to: (i) achieve higher degradation rate of the residual Butyraldehyde in fixed-bed via the residual Ozone generated from plasma system, and (ii) reduce the amount of ozone generated in the plasma/photocatalysis reactor. The values obtained for SIEplasma, $\left[\mathrm{C}_{4} \mathrm{H}_{8} \mathrm{O}\right]$ inlet, $\mathrm{RH}(\%)$ and ZSM-5 height show that ZSM-5 
intervened in the oxidation. This was possible due to its porous structure oxidizing the Butyraldehyde adsorbed via the Ozone/reactive species. Under humid conditions, the strong affinity of ZSM-5 for water molecules lead to a lower catalytic yield in the photocatalysis/fixed-bed reactor. A total reduction of Ozone concentration was attained: $~ 0,68 \mathrm{mg} \mathrm{m}^{-3}$ against 53,24 $\mathrm{mg} \mathrm{m}^{-3}$ under plasma/photocatalysis process without catalytic ozonation. The system plasma/photocatalysis/ZSM-5 allowed complete elimination of Butyraldehyde with a mineralization rate of $81.61 \%$. This opens doors for possible industrial applications of this system in automotive cabinets, hospitals' indoor odors, and domestic chimneys.

\section{References}

[1] ADEME, Pollutions olfactives: origine, législation, analyse, traitement, Ademe, Dunod, Angers (2005).

[2] Directive (eu) 2016/2284 du parlement européen et du conseil du 14 décembre 2016 concernant la réduction des émissions nationales de certains polluants atmosphériques, modifiant la directive $2003 / 35 / \mathrm{ce}$ et abrogeant la directive 2001/81/ce. Joue ; 17.12 .2016 ; 134

[3] P. Le Cloirec, Les composés organiques volatils (COV) dans l'environnement, Lavoisier, Tec\&Doc, Paris (1998).

[4] M. Wang, A. Lawal, P. Stephenson, J. Sidders, C. Ramshawa, Post-combustion $\mathrm{CO}_{2}$ capture with chemical absorption: a state-of-the-art review, Chem. Eng. Res. Des.89 (2011) 1609-1624.

[5] P. Monneyron, M.H. Manéro, S. Mathe, A combined selective adsorption and ozonation process for VOCs removal from air, The Canadian Chem. Eng. J. 85 (2007) 326-332.

[6] A.A. Assadi, A. Bouzaza, S. Merabet, D. Wolbert, Modeling and simulation of VOCs removal by non thermal plasma discharge with photocatalysis in a continuous reactor: Synergetic effect and mass transfer, Chem. Eng. J. 258 (2014) 119-127. 
[7] A.A. Assadi, A. Bouzaza, D. Wolbert, Photocatalytic oxidation of trimethylamine and isovaleraldehyde in an annular reactor: influence of the mass transfer and the relative humidity, J. Photochem. Photobiol. A Chem.236 (2012) 61-69.

[8] L. Sivachandiran, F. Thevenet, A. Rousseau, Regeneration of IPA saturated MnxOy surface: comparison of thermal, ozonolysis and non-thermal plasma treatments, Chem. Eng. J. 246 (2014) 184-195.

[9] G. Costa, A.A. Assadi, S. Gharib-Abou Ghaida, A. Bouzaza, D. Wolbert, Study of butyraldehyde degradation and by-products formation by using a surface plasma discharge in pilot scale: Process modeling and simulation of relative humidity effect, Chem. Eng. J. 3 (2017) 785-792.

[10] M. Guillerm, A.A ssadi, A. Bouzaza, D. Wolbert, Removal of gas-phase ammonia and hydrogen sulfide using photocatalysis, nonthermal plasma, and combined plasma and photocatalysis at pilot scale, Environ. Sci. Pollut. Res. 21 (2014) 13127-13137.

[11] A.A. Assadi, A. Bouzaza, I. Soutrel, P. Petit, K. Medimagh, D. Wolbert, A study of pollution removal in exhaust gases from animal quartering centers by combining photocatalysis with surface discharge plasma: from pilot to industrial scale,Chem. Eng. Process.111 (2017) 1-6.

[12] F. Thevenet, L. Sivachandiran, O. Guaitella, C. Barakat, A. Rousseau, Plasmacatalyst coupling for VOC removal and indoor air treatment: a review, J. Phys. DApp. Phys. 47 (2014) 1-14.

[13] J. Karuppiah, E. Linga Reddy, P. Manoj Kumar Reddy, B. Ramaraju, Ch. Subrahmanyam, Catalytic nonthermal plasma reactor for the abatement of low concentrations of benzene, Int. J. Environ. Sci. Technol. (2014) 311-318.

[14] P. Petit, P-J. Vialle, A. Maciuca, C. Batiot-Dupeyrat, J-M. Tatibouet, A.A. Assadi, A. Bouzaza, D. Wolbert, C. Vallet, Apparatus, system and process for gas treatment with dielectrical barrier discharge, EP 2762170 A1: 2013.

[15] P. Petit, P-J Vialle, A. Maciuca, C. Batiot-Dupeyrat, J-M Tatibouet, A.A. Assadi, A. Bouzaza, D.Wolbert, C.Vallet, Gas treatment device and method for assembling same, gas treatment system and method, EP 2803400 B1: 2014.

[16] W. Abou Saoud, A.A. Assadi, M. Guiza, A. Bouzaza, W. Aboussaoud, A. Ouederni, I. Soutrel, D. Wolbert, S. Rtimi, Study of synergetic effect, catalytic poisoning and regeneration using dielectric barrier discharge and photocatalysis 
in a continuous reactor: Abatement of pollutants in air mixture system, Appl. Catal. B Environ. 213 (2017) 53-61.

[17] E.F. Mohamed, G. Awad, H. Zaitan, C. Andriantsiferana, M.H. Manero, Transition metals incorporated zeolites as environmental catalysts for indoor air ozone decomposition, Environ. Technol. (2017) 878-886.

[18] H. Valdés, E.E. Padilla, C.A. Zaror, Influence of Chemical Surface Characteristics of Natural Zeolite on Catalytic Ozone Abatement, J. Ozone Sci. Eng.(2011) 279-284.

[19] J.P. Nogier, M. Delamar, X-ray photoelectron spectroscopy of $\mathrm{TiO}_{2} / \mathrm{V}_{2} \mathrm{O}_{5}$ catalysts, Catal.Today 20 (1994) 109-123.

[20] J.F. Moulder, W.F. Stickle, P.E. Sobol, K.D. Bomben, J. Chastain (Ed.) Handbook of X-ray Photoelectron Spectroscopy, Perkin-Elmer Corporation (Physical Electronics Division), Minnesota, USA, 1992.

[21] D.A. Shirley, High-resolution X-ray photoemission spectrum of the valence bands of gold, Phys. Rev. B 5 (1972) 4709-4714.

[22] N. Brodu, M.H. Manero, C. Andriantsiferana, J.S. Pic, H. Valdés, Role of Lewis acid sites of ZSM-5 zeolite on gaseous ozone abatement, Chem. Eng. J. (2013) 281-286.

[23] J.M. Roscoe, J.P.D. Abbatt, Diffuse reflectance FTIR study of the interaction of alumina surfaces with ozone and water vapor, J. Phys. Chem. (2005) 9028-9034.

[24] S. Gharib-Abou Ghaida, A.A. Assadi, G. Costa, A. Bouzaza, D. Wolbert, Association of surface dielectric barrier discharge and photocatalysis in continuous reactor at pilot scale: Butyraldehyde oxidation, by-products identification and ozone valorization, Chem. Eng. J.(2016) 276-283.

[25] W. Abou Saoud, A.A. Assadi, M. Guiza, A. Bouzaza, W. Aboussaoud, I. Soutrel, A. Ouederni, D. Wolbert, S. Rtimi, Abatement of ammonia and butyraldehyde under non-thermal plasma and photocatalysis: Oxidation processes for the removal of mixture pollutants at pilot scale, Chem. Eng. J. 344 (2018) 165-172. 
[26] I. Aouadi, J.M. Tatibouet, L. Bergaoui, $\mathrm{MnO}_{x} / \mathrm{TiO}_{2}$ Catalysts for VOCs Abatement by Coupling Non-thermal Plasma and Photocatalysis, Plasma Chem. Plasma Process. (2016) 1485-1499.

[27] T. Zadi, A.A. Assadi, N. Nasrallah, R. Bouallouche, P.N. Tri, A. Bouzaza, M.M. Azizi, R. Maachi, D. Wolbert, Treatment of hospital indoor air by a hybrid system of combined plasma with photocatalysis: Case of trichloromethane, Chem. Eng. J. 349 (2018) 276-286.

[28] N. Brodu, H. Zaitan, M.H. Manero, J.S. Pic, Removal of volatile organic compounds by heterogeneous ozonation on microporous synthetic alumina silicate, Water Sci. Technol. 202 (2012) 2020-2026.

[29] H. Valdés, V.A. Solar, E.H. Cabrera, A.F. Veloso, C.A. Zaror, Control of released volatile organic compounds from industrial facilities using natural and acid-treated mordenites: the role of acidic surface sites on the adsorption mechanism, Chem. Eng. J. 244 (2014) 117-127.

[30] H. Zaitan, M.H. Manero, H. Valdés, Application of high silica zeolite ZSM-5 in a hybrid treatment process based on sequential adsorption and ozonation for VOCs elimination, J. Environ. Sci. (2016) 59-68.

[31] H. Huang, W. Huang, Y. Xu, X. Ye, M. Wu, Q. Shao, G. Ou, Z. Peng, J. Shi, J. Chena, Q. Feng, Y. Zan, H. Huang, P. Hu, Catalytic oxidation of gaseous benzene with ozone over zeolite-supported metal oxide nanoparticles at room temperature, Catal. Today (2015) 627-633.

[32] A.A. Assadi, A. Bouzaza, D. Wolbert, Treatment of gaseous effluents by using surface discharge plasma in continuous reactors: Process modelling and simulation, The Canadian J. Chem. Eng. 93 (2015) 206-212.

[33] L. Zhang, L. Chen, Y. Li, Y. Peng, F. Chen, L. Wang, C. Zhang, X. Meng, H. He, F.S. Xiao, Complete oxidation of formaldehyde at room temperature over an Alrich Beta zeolite supported platinum catalyst, Appl. Catal. B Environ. 219 (2017) 200-208. 
[34] H.H. Kim, Y. Teramoto, T. Sano, N. Negishi, A. Ogata, Effects of Si/Al ratio on the interaction of nonthermal plasma and $\mathrm{Ag} / \mathrm{HY}$ catalysts, Appl. Catal. B Environ. 166-167(2015) 9-17.

[35] Y. Tong, L. Chen, S. Ning, N. Tong, Z. Zhang, H. Lin, F. Li, X. Wang, Photocatalytic reduction of $\mathrm{CO}_{2}$ to $\mathrm{CO}$ over the Ti-Highly dispersed HZSM-5 zeolite containing Fe, Appl. Catal. B Environ. 203 (2017) 725-730.

[36] A.A. Assadi, J. Palau, A. Bouzaza, D. Wolbert, A continuous air reactor for photocatalytic degradation of 3-methylbutanal: effect of different operating parameters and chemical degradation pathway, Chem. Eng. Res. Des. 91 (2013) 1307-1316.

[37] A.E. Wallis, J.C. Whitehead, K. Zhang, The removal of dichloromethane from atmospheric pressure air streams using plasma-assisted catalysis, Appl. Catal. B Environ. 72(2007) 282-288.

[38] A.A. Assadi, S. Loganathan, N. Tri Phuong, S. Gharib-Abou Ghaida, A. Bouzaza, N. Tuan Anh, D. Wolbert, Pilot scale degradation of mono and multi volatile organic compounds by surface discharge plasma/ $\mathrm{TiO}_{2}$ reactor: investigation of competition and synergism, J. Hazard. Mater.357 (2018) 305-313

[39] W. Elfalleh, A.A. Assadi, A. Bouzaza, D. Wolbert, J. Kiwi, S. Rtimi, Innovative and stable $\mathrm{TiO}_{2}$ supported catalytic surfaces removing aldehydes under UV-light irradiation, J. Photochem. Photobiol. A Chem. 343 (2017) 96-102.

[40] Y.X. Zeng, L. Wang, C.F. Wu, J.Q. Wang, B.X. Shen, X. Tu, Low temperature reforming of biogas over $\mathrm{K}^{-}, \mathrm{Mg}^{-}$and Ce-promoted $\mathrm{Ni} / \mathrm{Al}_{2} \mathrm{O}_{3}$ catalysts for the production of hydrogen rich syngas: Understanding the plasma-catalytic synergy, Appl. Catal. B Environ. 224 (2018) 469-478.

[41] P.D. Schulze, S.L. Shaffer, R.L. Hance, D.L. Utley, Adsorption of water on rhenium studied by XPS, J. Vac. Sci. Technol. A 1 (1983) 97.

[42] K. Winer, C.A. Colmenares, R.L. Smith, F. Wooten, Interaction of water vapor with clean and oxygen-covered uranium surfaces, Surf. Sci. 183 (1987) 67. 
[43] P. Cakir, R. Eloirdi, F. Huber, R. J. M. Konings, T. Gouder, An XPS and UPS Study on the Electronic Structure of ThOx $(x \leq 2)$ Thin Films, J. Phys. Chem. C 118 (2014) 24497-24503.

[44] A. Ayame, T. Kitagawa, X-Ray photoelectron spectroscopic measurement and chemical characteristics of silica, alumina and silica-alumina, Bunseki Kagaku 40 (1991) 673.

[45] D.W. Niles, H. Hochst, G.W. Zajac, T.H. Fleisch, B.C. Johnson and J.M. Meese,Anomalous regimes for GaAs etching in $\mathrm{Cl} 2-A r$ plasmas, J. Vac. Sci. Technol. A 6 (1988) 1584. 